\title{
Mag ich Unglück nit widerstan \\ Liebe, Tod und Glaubensfragen als \\ Komponenten einer Lied-Karriere im I6. Jahrhundert
}

\begin{abstract}
Maria von Ungarn war wohl eine der bekanntesten und einflussreichsten Frauen des I6. Jahrhunderts und ihre Vorliebe für Musik ist in den Zeugnissen der Zeit wie in der heutigen Literatur gut belegt. ${ }^{\mathrm{I}}$ In ihrer Jugend jedoch, noch bevor sie selbst das machtvoll-markante Bild der Frau in Witwentracht streute, war es zunächst das menschliche Schicksal Marias, das für Aufsehen sorgte: Ein junges, verliebtes Paar der „High Society“ wird von einem Schicksalsschlag getroffen; der Mann stirbt und die Gattin bleibt in Trauer zurück. Dieses Unglück sowie weitere Ereignisse in Marias Leben fanden auch Eingang in die Liedproduktion, die mit ihren Erzeugnissen ein wichtiges Informations- und Unterhaltungsmedium der Zeit darstellte. Insbesondere ein Lied, Mag ich Unglück nit widerstan, ist in besonderer Weise mit Marias Person verknüpft. Im Folgenden sollen nun zunächst mögliche Faktoren für die Popularität der Königin von Ungarn in der Gattung Lied ausfindig gemacht werden, um daraufhin die weiteren Erscheinungsformen und Wandlungen von Mag ich Unglück in Relation zu Marias Werdegang zu betrachten. ${ }^{2}$ Manche Stränge der Liedgeschichte entfernen sich dabei von dieser Persönlichkeit, andere markieren und kommentieren mit ihrem Auftreten wichtige Stationen auf deren Lebensweg.
\end{abstract}

\section{LIEBE UND TOD}

Maria wurde als Tochter von Philipp dem Schönen und Johanna von Kastilien („der Wahnsinnigen“) I 505 in Brüssel geboren und am Hof ihrer Tante Margarethe von Österreich in Mecheln erzogen. Im Alter von acht Jahren ließ sie ihr

I Glenda G. Thompson, „Music in the Court Records of Mary of Hungary“, in TVNM 34 (I984), S. I32-I73; dies., „Mary of Hungary and Music Patronage“, in The Sixteenth Century Journal I 5 (I984), S. 40I-4I8; Peter Király, „Königin Maria von Habsburg und die Musik“, in Maria von Ungarn (1505-1558) eine Renaissancefürstin, hrsg. von Martina Fuchs und Orsolya Réthelyi, Münster 2007 (Geschichte in der Epoche Karls V. 8), S. 363-379.

2 Als Untersuchungsmaterial wurden in Bezug auf die Verbreitung von Liedtexten in erster Linie gedruckte Quellen herangezogen. 
Großvater Kaiser Maximilian I. nach Wien bringen, da ihr eine Rolle in seiner strategischen Familienpolitik zugedacht war. Im Rahmen des sogenannten Wiener Fürstentags von I 5 I 5 wurde ihre Eheschließung mit Ludwig II. von Ungarn, die bereits $1506 / 7$ angebahnt wurde, ${ }^{3}$ erneut vertraglich abgesichert. Da Maria zu diesem Zeitpunkt erst neun Jahre alt war (und ihr zukünftiger Gatte sogar noch ein Jahr jünger), wurde ihre Erziehung zusammen mit ihrer zukünftigen Schwägerin Anna von Ungarn in Innsbruck fortgesetzt. Nach dem Tod Maximilians und der Wahl Karls zum römisch-deutschen König I5 I9 wurden die beiden vertraglich geschlossenen Ehen zur Stabilisierung des Machtanspruchs eingelöst. Zunächst fand die Hochzeit von Marias Bruder Ferdinand (dem zukünftigen Kaiser Ferdinand I.) und Anna am 26.5.I52 I in Linz statt und im darauffolgenden Jahr diejenige Marias in Buda.

Trotz der arrangierten Ehe war Maria ihrem Gatten offenbar sehr zugetan. Im Vorfeld der Hochzeit konnte sie bereits ihre Entschlossenheit an Ludwigs Seite zu stehen unter Beweis stellen. Bei ihrer Anreise drohte ein Angriff durch den osmanischen Sultan Süleyman auf Belgrad (Beograd), und in Pressburg (Bratislava) wurde Maria aufgrund der unsicheren Situation geraten, wieder umzukehren. Sie setzte ihre Reise jedoch unbeirrt fort. Ebenso aus politischem Kalkül wie aus ehrlicher Zuneigung und Sehnsucht könnte sie später auch den Entschluss gefasst haben, Ludwig sogar im Feldlager zu besuchen. ${ }^{4}$ Aus der frühen Zeit des Zusammenlebens von Maria und Ludwig sind zwei Berichte aus dem Umfeld des Paares erhalten geblieben, die - damit vielleicht auch die Konventionen der Zeit erfüllend - das liebevolle Verhältnis der beiden dokumentieren. In einem Brief des Gesandten Ferdinands, Andrea da Burgo, vom 2I. August I 52 I lautet die Passage: „Rex [Ludwig] ... est valde captus amore reginae non solum corporis sed virtutum ejus; et Regina mutuo eum amat et ambo sunt satis in

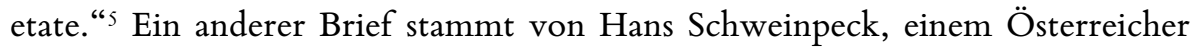
aus Marias Gefolge, der an seinen Sohn schrieb:

Für wahr der Kunig ist rechtschaffen, haben einander aus dermassen lieb das sehen die valschen hund [Anm: gemeint sind hier die ungarischen Adligen und Kleriker], unt wo sy konnten davor sein, Sy lassen den Kunig nitgehen zu meiner gnedigsten Frauen, möchten leiden, wir zugen wider haimb ein jar oder zwei, damit sie ir sach desto pass machen kunnten, aber

3 Enikö Spekner, „Die Geschichte der habsburgisch-jagiellonischen Heiratsverträge im Spiegel der Quellen“, in Fuchs/Réthelyi, Maria von Ungarn, S. 25-46.

4 Ursula Tamussino, Maria von Ungarn. Ein Leben im Dienst der Casa de Austria, Graz u.a. I998, S. 66 . und S. 79.

5 Zitiert nach Karl Stoegmann, „Über die Briefe des Andrea da Burgo“, in Sitzungsberichte der kaiserlichen Akademie der Wissenschaften, Phil.-Hist. Classe 24 (I 857 ), S. 68, Fn. 20. 
Liebe, Tod und Glaubensfragen als Komponenten einer Lied-Karriere im I6. Jahrhundert

wirt nit beschehen, sind noch des synns, zu nechst und möglich bei dem Kunig zu bleiben unt allen abenteur zu besteen. ${ }^{6}$

In diesem Brief spiegelt sich auch die Situation bei Hofe wider, die von der Missgunst zwischen den ungarischen und „deutschen“ Hofleuten geprägt war.

Selbst mit dem Tod Ludwigs endete Marias Liebe zu ihrem Gatten nicht. Die von ihren Brüdern vorgeschlagenen Pläne für eine erneute Verheiratung wies sie stets zurück. Ihre Antwort auf das Angebot, den König von Schottland zu heirateten lautete:

Aber dieweil der almechtig durch sein gottlichen willen meinen freundlichen hertzliebsten hern und gemahel genomen hatt und mich in dissen standt hatt haben wellen, so hab ich mier gantzlich fiergenomen $[\ldots]$ pis in mein grub zw bleiben. ${ }^{7}$

Schließlich bleibt als letztes und eindrücklichstes Zeugnis für die Zuneigung Marias zu Ludwig der Abschluss ihres Testaments vom 3. Dezember I 555:

Aiant porté depuis la mort du feu roy, mon mary, a qui dieu face paix, ung ceur d'or, qu'il a ausy porté jusques a sa mort, je ordonne que le dit ceur avec la chennette, ou il pent, soit fondu et donné ce quy en viendra aulx poures. Car puisqu'il a fait compaignie jusques au dernier aulx persones quy, ores qu'ilz ont esté separés de cy longtamps de presence, ne l'ont esté d'amour et affection, c'est reson qu'il ce consomme et sange d'espece comme les corps des justement aimans ont fait. ${ }^{8}$

6 Ebda.

7 Zitiert nach Wilhelm Bauer und Robert Lacroix (Hrsg.), Die Korrespondenz Ferdinands I. Band II/1: Familienkorrespondenz 1527 und 1528, Wien 1937 (Veröffentlichungen der Kommission für Neuere Geschichte Österreichs 30), S. 263 f. Während der Brief an Ferdinand auf Französisch abgefasst ist, handelt es sich hier um eine Art Memorandum von Marias Hand, datiert mit dem IO. Juli I 528 in Ödenburg.

8 Aus dem Testament vom 3.I2.I555, niedergeschrieben in Brüssel; zitiert nach Hans von Voltelini, „Urkunden und Regesten aus dem K.u.K. Haus-, Hof- und Staats-Archiv in Wien“, in Jahrbuch der Kunsthistorischen Sammlungen des Allerhöchsten Kaiserhauses I I (I890), II. Teil I-LXXXIV, hier S. LXVII, Nr. 6477.

Übersetzung nach Tamussino, Maria von Ungarn (wie Anm. 4), S. 272: „Seit dem Tod des verewigten Königs, meines Gemahls, habe ich ein goldenes Herz nicht mehr abgelegt, das auch er bis zu seinem Tod getragen hat. Ich wünsche, dass dieses Herz, zusammen mit der kleinen Kette, an der es hängt, eingeschmolzen und der Erlös den Armen gegeben wird. Denn im Hinblick auf die Tatsache, dass es zwei Menschen bis zu ihrem letzten Atemzug begleitet hat, die zwar lange Zeit körperlich, niemals aber in Liebe und Zuneigung getrennt waren, so ist es angemessen, dass es vergeht und seine Natur sich wandelt, wie es auch mit den Körpern dieser Liebenden geschehen ist.“ 
Kommt diese Darstellung in den Quellen dem realen Verhältnis des Königspaares nahe, so muss Maria vom Tod ihres Gatten im Umfeld der Schlacht von Mohács schwer getroffen gewesen sein. Überdies setzte jenes Ereignis auch ihrem bisher weitgehend geordneten Leben am Hof ein Ende.

Die Schlacht von Mohács stellte für das neuzeitliche Europa tatsächlich nichts weniger als eine existenzbedrohende Katastrophe dar. Der Gefahr des herannahenden osmanischen Heeres war man sich spätestens seit der Einnahme von Belgrad im Sommer I52 I bewusst, doch immer wieder verhallten die Aufrufe von ungarischer oder kaiserlicher Seite an das Reich zur Hilfe gegen die Türken ungehört. Zudem hatte Ludwig auch im eigenen Land keinen guten Stand. Die ungarischen Magnaten hatten in Ludwigs Jugend, als die Herrschaft ohne den Rückhalt einer machtvollen Persönlichkeit ausgeführt wurde, ihre Stellung gegenüber der Krone ausgebaut und es wird häufig berichtet, dass der Hof in finanziellen Nöten steckte. ${ }^{9}$ Ferner stellte János Zápolya ebenfalls Ansprüche auf den ungarischen Thron und suchte die ungarischen Landsleute mit Verweis auf den schlechten „deutschen“ Einfluss am Hof auf seine Seite zu ziehen.

Am 29. August unterlag König Ludwig den zahlenmäßig weit überlegenen Truppen des Sultans. Was man sich nicht hatte vorstellen wollen wurde zur Gewissheit: Die Osmanen zogen in Buda ein und besetzten einen Großteil des ungarischen Königreiches. Wäre es die Absicht Süleymans gewesen, hätte das osmanische Heer auf diesem Feldzug wahrscheinlich ohne größere Anstrengungen sogar Wien einnehmen können. Mit Hilfe von zahlreichen Flugschriften, den sogenannten Newen Zeyttungen, verbreitete sich die Nachricht von dieser Katastrophe in Windeseile im ganzen deutschsprachigen Raum. ${ }^{10}$ Die Bedrohung durch die Osmanen blieb das gesamte I6. Jahrhundert hindurch aufrecht, so dass auch das Thema der Türkengefahr - und insbesondere Mohács als symbolischer Beginnpunkt der Misere - allgegenwärtig blieb.

9 Vgl. erneut den Brief Schweinpecks an seinen Sohn: Stoegmann, „Über die Briefe des Andrea da Burgo“, S. 68 [224], Fn. 20 und ebda. S. Iо [I66].

IO Etwa New zeyttung wie der Turckischen Keyser mit dem König von Vngern dye schlacht gethan hat, [Erfurt: Wolfgang Stürmer] I 526 [VDI6 N I040; weiterer Druck Leipzig VDi6 ZV 2263 I] oder Newe zeyttung, wie es mit der schlacht zwüschen dem Künig von Ungern und dem Türckischen Keyßer ergangen, [Speyer: Jakob Schmidt] I526 [VDi6 N I055; weiterer Druck Straßburg VDi6 ZV 22629]; Nyge tydynghe. De Slachtyngh des Turckesken Keysers, myt Ludowico, do tor tidt Könynck to Vngeren, Hamburg: Johann Wickradt d.Ä. I 526 [VDI6 ZV I I 520]; Hernach volgt des Bluthunds der sich nennet eyn Türckisch Keyser, gethaten, so er vnd die seynen, nach eroberung der schlacht, auff den. xxviij. tag Augusti nechstuergangen, geschehen, an vnsern mitbrüdern der Vngrischen landtschafften gantz vnmenschlich getryben hat, [Nürnberg: Hans Hergot] I 526 [VD I6 ZV 2 I 06]; Newe zeyttung Wie die Schlacht in Vngern mit dem Türckischen Keyser ergangen, [Würzburg: Balthasar Müller von Würzburg] I 526 [VDi6 N I046]. 


\section{KÖNIG UND KÖNIGIN VON UNGARN IM LIED I}

Die Ereignisse im Ungarn des Jahres I 526 blieben auch in der Liedproduktion nicht unbeachtet. Unter mehreren Liedern zu Vorgeschichte und Verlauf der Schlacht ist Ein neuer Bergreihen von König Ludwig aus Ungarn, eine Kontrafaktur $\mathrm{zu}$ Fröhlich so will ich singen, das am meisten verbreitete (gelegentlich auch mit dem der Situation angemesseneren Incipit „Kleglich so will ich heben an“ anzutreffen). ${ }^{11}$ Darin werden die Heirat Ludwigs mit Maria, der Neid der Ungarn auf das scheinbar deutsch und böhmisch dominierte Hofleben und ein Verrat an die Türken durch János Zápolya, der Ansprüche auf Ungarns Thron geltend machen wollte, polemisierend besungen.

Ein anderes Lied schildert die Ereignisse aus der Sicht Marias: Ach Gott was soll ich singen. ${ }^{\mathrm{I}}{ }^{2}$ Hier wird das oben skizzierte Bild einer liebevollen Beziehung des ungarischen Königspaares auch einer breiteren Öffentlichkeit vermittelt. Bemerkenswert ist die Wahl des Tones für diese Kontrafaktur: Es wonet lieb bei liebe. ${ }^{13}$ Der ursprüngliche Liedtext erzählt eine unglückliche Liebesgeschichte nach dem Muster von Pyramus und Thisbe, das der Zeit angeglichen meist von einer Herzogin oder einer Königstocher und einem Ritter handelt. ${ }^{I 4}$ Ausgangspunkt ist eine von Außenstehenden nicht geduldete Liebe, die ein Paar zu heimlichen Verabredungen zwingt. Durch ein unvorhersehbares, von der Außenwelt verschuldetes Ereignis bei einem dieser Treffen kommt es zu einem Missver-

I I Rochus von Liliencron, Die historischen Volkslieder der Deutschen vom 13. bis 16. Jahrhundert, Bd. 3, Leipzig I867, Nr. 403. Eine geistliche Vorlage dieses Liedes - die nach Ludwig Erk und Franz Magnus Böhme, Deutscher Liederhort, 3 Bde., Leipzig I 893/94, Bd. 2, Nr. 276, hier S. 8I selbst bereits die Kontrafaktur einer weltlichen Tageweise darstellt - findet sich in einem Liedflugblatt Ein schöne Tageweise, wie Maria ist empfangen worden ohne Erbsünde (Frieder Schanze, „Gestalt und Geschichte früher deutscher Lied-Einblattdrucke nebst einem Verzeichnis der Blätter mit Noten“, in NiveauNischeNimbus. Die Anfänge des Musikdrucks nördlich der Alpen, hrsg. von Birgit Lodes, Tutzing 2010 (Wiener Forum für ältere Musikgeschichte 3), S. 3694IO, Verzeichnis Nr. 5; Rolf Wilhelm Brednich, Die Liedpublizistik im Flugblatt des 15. bis 17. Jahrhunderts, Baden-Baden 1974/75, Bd. 2: Katalog der Liedflugblätter des 15. und 16. Jahrhunderts, Nr. 28 und Abb. 9. Auch digital unter http://mdzio.bib-bvb.de/ einblattdrucke/ images/3000000Io_o_r.pdf einsehbar. Siehe auch Franz M. Böhme, Altdeutsches Liederbuch. Volkslieder der Deutschen nach Wort und Weise aus dem 12. bis zum 17. Jahrhundert, Leipzig I877, Nr. 392.

I2 Liliencron, Die historischen Volkslieder, Bd. 3, Nr. 404.

I3 Böhme, Altdeutsches Liederbuch, Nr. I8: „Ritter und Herzogstocher“. Erk/Böhme, Liederhort, Bd. I, Nr. 86.

I4 Etwa Ein schöne Tagweys, Es wonet lieb bey liebe, etc. von eyner jungen Hertzogin vnd von eynem Ritter, [Nürnberg: Kunigund Hergotin] ca. I530 [VDI6 ZV I 5872], daneben auch VDi6 ZV 542 I-5423 und in Liedersammlungen wie D-HEu Cod. Pal. germ. 343 oder dem Ambraser Liederbuch. Bereits im Jahr I 5 I 5 tauchen Kontrafakturen in dem Ton Es wonet lieb bei liebe auf: Johann Böschenstein, Zwo Lieder, von den syben Worten JEsu Christi, vnd von den zehen Gebotten GOttes, o.O. I5 I5 [VDi6 B 636I und B 6387]. 
ständnis, und aus Verzweiflung begeht der Liebhaber Selbstmord. Die Frau erscheint zu spät am vereinbarten Treffpunkt, findet den Toten und nimmt sich, da sie ohne den Geliebten nicht weiterleben will, ebenfalls das Leben. Diese Vorlage wurde sicherlich nicht nur aufgrund ihres Bekanntheitsgrades gewählt. Zwar entsprechen die Geschehnisse in Ungarn nicht dem ausgeführten ErzählSchema, doch sind es zwei Elemente, die ein Anknüpfen des neuen Textes an die mit dem gewählten Ton transportierte Erzählung ermöglichen: eine große Liebe und ein durch ein Ereignis der Außenwelt verschuldeter vorzeitiger Tod. Besonders großen Raum nimmt im neuen Liedtext die Trauer und Verzweiflung Marias ein, die in den letzten zwei Zeilen Gott um Trost und Besserung ihrer Situation anruft.

I. Ach Gott was soll ich singen Mein freud die ist mir ferr Seyt sich von mir wil schwingen Mein aller liebster Herr Seyt das im ist kummen potschafft Das lig im Hungerlande Der Türck mit heeres krafft.

2. Wölt ir euch von mir schaiden O wee ob allem wee Bringt meinem hertzen leyden Förcht ich sech euch nicht mee Er sprach es mag nit annders sein Ich mueß helffen erretten Das vatterlande mein

3. Wann mich thuet hart erbarmen In meines hertzen grund Im gantzen Lanndt der armen. Die der Türckische hundt Ellend erwürgt in disem krieg Ich wil bald wider kummen Verleycht vnns Gott den sieg.

4. Also schied er von hinnen Der außerwelte mein Mit Ritterlichen sinnen Bot mir die hande sein Den ich darnach sach nymmer mer Mit seiner Ritterschafft Mit Roß harnisch vnnd wehr Is Im Original fälschlich: „mnn“
5. Mein hertz das war mir schwere Mit seuftzen jamer klag Ye lenger vnnd ye mere Die nacht bis an den tag Wol vmb den liebsten Herren mein Mit senen vnnd verlangen Mit angstlicher pein.

6. Darnach in dreyen tagen Kam mir trawrig potschafft Wie der Türckh het geschlagen Mit seiner herres krafft Das Hungerisch heer mit grosser schlacht

Ee dann mein lieber Herre Sein volchk zusamen bracht.

7. Darzue wer auch verloren Mein aller liebster Herr König Ludwig hochgeboren Das man ${ }^{15}$ in weit vnnd ferr Nit weste oder finden kundt Ob er noch wer bey leben Gefangen oder wundt

8. Erst ward mein hertz jm leybe Durch gossen mit onmacht Wer fandt betruebters weybe Mein hertz schray vnnd gedacht O dw liebster gemahel mein Sol ich dich nymmer sehen Vnnd ewig on dich sein. 
Liebe, Tod und Glaubensfragen als Komponenten einer Lied-Karriere im I6. Jahrhundert

9. Erst meret sich mein schmertzen

Vnnd vnaussprechlich klag

Mit ganntz betruebtem hertzen

Verzeer ich manchen tag

Hin was mein freüd wunn vnnd trost

Fürbas kein freüd auff erden

Meim hertzen wird genoß.

IO. Nach dem der Türck auch kame

Vnnd Ofen die Hauptstat

Gewaltigklich einname

Vnnd auch verwuestet hatt

Das guet vnnd reyche Hungerlanndt

Die leüt fieng vnnd erwürget

Stett vnnd Dörffer verbrandt.
I I. Nun mueß mich ymmer rewen

Mein edler Herre frumb

Das er in solchen trewen

Für sein volckh kame vmb

Vnnd mich verließ trostloß ellend

Die weyl ich leb auff erden

Gott es zum besten wendt.

AMEN.

Zwey schöne lieder, Eyn Geystlichs vnnd ein weltlichs, von der Königin vo[n] Hungern, Frawen Maria, vnd jrem gemahel König Ludwig als er vo[n] jr jn streyt zoch wider den Türcken ${ }^{16}$

Dieses Lied ist in Flugschriften überliefert und tritt dort stets an zweiter Position auf. Voraus geht ihm immer ein weiteres Lied der Königin von Ungarn, das im Gegensatz zum zweiten als ein geistliches Lied bezeichnet wird. Die Eingangszeile lautet „Mag ich Unglück nit widerstan“. Dieses Lied ist nicht nur in der Flugpublizistik vertreten, sondern fand auch in lutherischen Gesangbüchern Verbreitung. Auch dort ist es in einigen Fällen mit einem Beisatz versehen, der es als Lied der Königin von Ungarn ausweist. In diesem dreistrophigen Lied wird weder die Liebesbeziehung zu Ludwig angesprochen (er tritt nicht einmal in Erscheinung), noch die Katastrophe von Mohács in irgendeiner Art und Weise erwähnt. Der Bezug zu Maria wird in den Liedtext verwoben mit einem Akrostichon geleistet: Liest man ausschließlich die erste Silbe jeder Strophe, ergibt sich der Name MA-RI-A. ${ }^{17}$ Der Aussage nach trägt das Lied dagegen eindeutig reformatorische Züge (siehe den nachfolgenden Textvergleich): Ein „Ich“ kann seinen Glauben nicht öffentlich bekennen, da es von seiner Umge-

I6 Flugschrift ohne Angabe von Druckort und -datum [VDi6 Z 703; Wien: Hieronymus Vietor I 530].

I7 Eine weitere Interpretation deutet an, dass die Initialen des Textbeginns „Mag ich Unglück nit widerstan“ (M-I-U-N-W) für „Maria in Ungarn nun Witwe“ stehen könnten. Karl W. Schwarz, „Leonhard Stöckel (I 5 IO-I 560): ,Lumen et Reformator Ecclesiarum Superioris Hungariae"“, in Deutsche Sprache in der Slowakei. Festschrift für Prof. Dr. Ilpo Tapani Piirainen zum 65. Geburtstag, hrsg. Peter Ďurčo, Ružena Kozmová and Daniela Drinková, Bratislava 2009, S. 313-335, hier S. 324 [online verfügbar unter: http://www.sung.sk/fotkyI0204/Publikationen/Deutsche_Sprache_in_der_Slowakei_Inhaltsverzeichnis.pdf]. 
bung unterdrückt wird. In Gott vertrauend hofft es schließlich auf eine bessere Zukunft. Wie ist dieser Inhalt mit der Person Marias, der Schwester des für den katholischen Glauben eintretenden Kaisers, zu vereinbaren?

Textvergleich der weltlichen und der geistlichen Fassung des Liedes Mag ich Unglück nit widerstan

Flugschrift, Zwey newe lieder, Das Erste,

Künig ein herr ob allem reych,

Nürnberg: Georg Wachter o.J.

$M A g$ jch vnglück nit widerstan, gut hoffnung han,

es wirdt nicht allzeyt weren.

Mancher der für ein grossen pracht, wirdt hoch geacht,

gschicht als mit kleynen ehren,

Wenn er die gnad,

von Gott nicht hat,

wenn er gedecht,

was jm gebrecht,

all ding sie thund verkeren.

Richt wie jch wöll yetzundt meyn sach, so thun jch gemach, merck eben auff die schantze.

Ich thu nit dergleich sams mich angehe, darbey jch verstehe,

jr schalckheit vnd finantze,

Die sie stäts treyben,

voller vntrew bleyben,

gegen jrem herren,

des rayen sie werden,

noch selber müssen tantzen.

$A$ ls dings ein weyl ein sprichwort ist, zu diser frist,

jch wil sein wol erbeyten.

Mit gedult man vil sach noch vber windt, sie seind so geschwind,

hilfft nit zu allen zeiten,

Auff diser erden,

erst wil jch mich ergeben,

gegen meinem herrn,

gantz willig vnd gern,

glück zu auff vnser seyten.
Der Durchleuchtigsten Großmechtigen

Fürstin ... New gaystlich Lied,

[Augsburg: Heinrich Steiner]

Mag ich vnglück nit widerstan, muß vngnad han,

der welt vmb mein recht glauben,

So waiß ich doch Gott ist mein kunst, sein huld vnd gunst,

die muß man mir erlauben

Gott ist nit weyt,

ain klaine zeyt,

er sich verbirgt,

biß er erwürgt,

die mich seins worts berauben.

$R i$ cht wie ich wöll yetzund mein sach, weil ich bin schwach,

vnd mich Gott forcht lest finden,

So waiß ich doch kain gwalt bleibt vest,

der nit zu letzst,

als zeytlich muß verschwinden,

das ewig gut

macht rechten mut,

darbey ich bleib,

wag gut vnd leib,

Gott helff mir überwinden.

$A$ ls dings ain weil ain sprichwort ist, herr Jesu Christ,

du selbst würst für mich streitten,

Vnnd sehen auff das vnglück mein,

als wer es dein,

soß wider micht wirt reitten,

$\mathrm{muß}$ ich dan[n] dran,

auff diser pan,

welt wie du wildt,

Got ist mein schildt,

glück zu auff vnser seitten. 
Tatsächlich scheint dieser geistliche Liedtext, auf den ich an spätere Stelle weiter eingehen werde, nicht der ursprüngliche zu sein, sondern er stellt eine Kontrafaktur auf ein weltliches Lied mit gleichem Incipit dar, ${ }^{18}$ das sich auch in einem Satz von Ludwig Senfl erhalten hat. ${ }^{19}$ Neben den Eingangszeilen der jeweiligen Strophen (und damit dem Akrostichon) teilen sich die beiden Liedtexte in einigen Versionen auch die Schlusszeile des Liedes.

\section{DAS WELTLICHE MAG ICH UNGLÜCK NIT WIDERSTAN IM SPIEGEL DES AKROSTICHONLIEDES}

Dem Inhalt nach verbindet der Liedtext moralisch-didaktische Elemente mit denen des Fortuna-Topos: Das „Ich“ befindet sich offensichtlich in einer unerfreulichen und unglücklichen Lage; es folgt die Mahnung, sich in das von Gott gegebene Schicksal zu fügen und nicht wie andere in unzulässiger Pracht zu leben. In der zweiten Strophe gibt das „Ich“ an, geduldig auf seine Chance zu warten und skizziert noch einmal das abschreckende Bild des ungehörigen und untreuen Lebenswandels der anderen. Die dritte Strophe beginnt mit einem Lob der Geduld, der Versicherung des Dienstes am Herrn und endet mit dem Wunsch „Glück zu auf unser Seiten“. Klagen über die Schlechtigkeit der Welt, verbunden mit einem moralischen Appell, stellen in den Liedtexten zu Beginn des I6. Jahrhunderts keine Seltenheit dar. Unter den zahlreichen von Ludwig Senfl vertonten Liedtexten finden sich in dieser Kategorie etwa Was ist die Welt, Der Welte Lauf und Was wird es doch des Wunders noch; ${ }^{20}$ letzteres thematisiert differenzierter das rücksichtslose Streben nach Geld. Als Beispiele der Verbindung der Weltklage mit der Hoffnung auf Glück in der Zukunft lassen sich aus diesem Korpus Geduld um Huld und Die Not sucht Weg benennen. ${ }^{21}$ Im Zusammenhang mit Maria wurde der Liedinhalt häufig auf die oben bereits angedeuteten Verhältnisse am Hof in Buda projiziert, wo man der „deutschen“ Königin wie in dem Brief Schweinpecks bereits angedeutet - nicht immer mit Wohlwollen begegnete. Oder aber das Lied wurde pauschal zu den Huldigungsliedern

I 8 Der Einzige der diese Deutung anzweifelte war Karl Budde, der von einem „weltlichpolitischen Kontrafaktum des [geistlichen] Liedes“ spricht; Karl Budde, „Kleinigkeiten zum Kirchenliede“, in Monatsschrift für Gottesdienst und kirchliche Kunst I (I 896), S. 56-59, hier S. 59. Als Gegenargumente lassen sich die Quellenlage (siehe Anhang), als auch die allgemeine Annahme, dass häufiger weltliche Lieder mit geistlichen Texten kontrafaziert werden anführen.

I9 Ludwig Senfl, Sämtliche Werke (im Folgenden SW), Bd. V: Deutsche Lieder zu vier bis sechs Stimmen, hrsg. von Arnold Geering und Wilhelm Altwegg, Wolfenbüttel I949, Nr. I3.

20 Senfl, $S W$ IV, Nr. 38 ; V, Nr. 9 bzw. VI, Nr. 9; IV, Nr. 25 und 26.

2 I Senfl, SW II, Nr. 6; IV, Nr. 27. 
Senfls gezählt, die Bente in den Jahren zwischen I5I9 und I 523 verortete. ${ }^{22}$ Friedrich Spitta, der sich mit den beiden Versionen von Mag ich Unglück eingehend beschäftigte, nahm eine Entstehung des weltlichen Texts im Zeitraum der Jahre I $522 / 23$ an. ${ }^{23}$

In den erhaltenen Quellen tritt dieser weltliche Liedtext jedoch erstmals in Georg Forsters erstem Liederbuch von I 539 auf, wo er in Verbindung mit einem vierstimmigen Satz von Ludwig Senfl als Nr. I02 abgedruckt ist (für eine Übersicht zur Quellenlage des Senfl'schen Satzes siehe Anhang 3). Die früheste bekannte Quelle für diesen musikalischen Satz stellt allerdings die Lautentabulatur von Hans Judenkünig aus dem Jahr I 523 dar, was sich gut mit Spittas These vereinbaren lässt; dort sind ein zweistimmiger $(T, B)$ und ein dreistimmiger Auszug (T, B, D) in deutsche Lautentabulatur abgesetzt. ${ }^{24}$ Das frühe Datum der Tabulatur macht deutlich, dass die Komposition Senfls keinesfalls nach der Schlacht von Mohács, sondern geraume Zeit davor entstanden sein muss. Es stellt sich nun die Frage, ob Senfl dieses Lied überhaupt mit dem Gedanken an Maria von Ungarn vertonte. Im 5. Band der Edition Ludwig Senfl, Sämtliche Werke verneint Wilhelm Altwegg diese Annahme in den Anmerkungen zu den Texten: „Das wieder aus der gesellschaftlichen Welt erwachsene und - mit wenig dichterischem Können - deren Unarten anprangernde weltliche Trostlied hat trotz seinem Akrostichon MA-RI-A kaum schon etwas zu tun mit der Königin von Ungarn. “25

Im Gegensatz zu den Textzeugen der geistlich gefärbten Variante wird der Satz Senfls, der - wenn er mit Text überliefert ist - stets dem weltlichen Text verbunden ist, ${ }^{26}$ nie mit einem Beisatz in der Art „Der Königin von Ungarn Lied“ versehen. ${ }^{27}$ Das Akrostichon „Maria“ erscheint in der Tat sehr unspezi-

22 Martin Bente, Neue Wege der Quellenkritik und die Biographie Ludwig Senfls. Ein Beitrag zur Musikgeschichte des Reformationszeitalters, Wiesbaden I968, S. 306.

23 Friedrich Spitta, „Die ungarischen Königslieder. Ein Blatt aus der hymnologischen Geschichte der Reformationszeit", in Monatsschrift für Gottesdienst und kirchliche Kunst I4 (I909), S. 325-342, hier S. 328-332.

24 Hans Judenkünig, Ain schone kunstliche vnderweisung, Wien: Hans Singriener I523 [Brown I $\left.523_{2}\right]$, fol. b2 ${ }^{\mathrm{v}}$ und fol. $\mathrm{c} 3^{\mathrm{v}}-\mathrm{c} 4^{\mathrm{r}}$.

25 Senfl, $S W$ V, S. I 2 I.

26 Allein die Handschrift D-HRD Fü 9822-9823 konnte von mir noch nicht eingesehen werden. Da von dieser Quelle allein Diskant und Bass erhalten sind, ist der Satz dort wahrscheinlich nur mit dem Textincipit verzeichnet.

27 Die Angabe in Senfl, SW V, S. I20, dass „Königin von Ungarn Lied“ im Basler Stimmbuchsatz zu finden wäre, ist ebenso wenig zutreffend wie die Beschreibung Hans Joachim Mosers eines ähnlichen Vermerks in Forster I (RISM I $539^{27}$; Geschichte der deutschen Musik, Bd. I, Stuttgart/Berlin I920, S. 459). Moser stützte sich hierbei auf eine Angabe von Otto Kade, „Einleitung“, in Einleitung, Biographieen, Melodieen und Gedichte zu Johann Ott's Liedersammlung von 1544, hrsg. von Robert Eitner, Ludwig Erk und Otto Kade, Berlin I876 (PÄMw 4), S. 28. 
fisch, ist doch Maria nicht nur ein sehr gebräuchlicher Name, sondern könnte auch eine allgemeine Anrufung der Gottesmutter Maria darstellen. Dagegen sind zahlreiche Lieder der Zeit bekannt, die mit Hilfe des Akrostichons einen sehr gezielten Hinweis auf eine bestimmte Person geben, indem sie deren korrekte formale Anrede wiedergeben. Dazu zählt etwa das Lied Genad mir Herr ewiger Gott, das wie die geistliche Version von Mag ich Unglück häufig in protestantischen Liederbüchern auftaucht. Es trägt (nach der Ausgabe des Babst'schen Gesangbuchs von I545) über 9 Strophen verteilt das Akrostichon „GE-OR-GI MARCK-GRAF ZV BRAN-DEN-BVRCK““. ${ }^{28}$ Kunstvoller finden sich der Name und Titel einer adligen Person in dem Lied Herr durch Barmhertzigkeyt und Gnad in nur vier Strophen eingewoben: ${ }^{29}$ Ein Akrostichon ergibt „HERR-ZOG OT-HEIN“ und ein Telestichon ergänzt: „PFALTZ-GRAFF-E BEY REIN“. Bei diesen Liedern, die die Namen adeliger Personen tragen, ist das Akrostichon wohl immer als Widmung zu deuten, obwohl ein Akrostichon auch die Funktion übernehmen konnte, einen Verfassernamen zu nennen. Bekannte Beispiele hierfür aus dem deutschen Sprachraum sind etwa die Lieder Adams von Fulda oder Lust hab ich ghabt zur Musica von Ludwig Senfl. ${ }^{30}$

Allerdings finden sich unter den von Senfl vertonten Liedern tatsächlich einige Beispiele, die allein einen weiblichen Vornamen in Form eines Akrostichons preisgeben (vgl. Anhang I). Einige von ihnen können gleichwohl bestimmten, meist adeligen Personen zugeordnet werden. So etwa die Lieder, die das Akrostichon des selteneren Doppelnamens „Maria Jacobe“ tragen und wohl für Maria Jakobäa von Baden geschrieben wurden, die am 5. Oktober I 522 den bayerischen Herzog Wilhelm IV. ehelichte. Dazu zählen die zwei Vertonungen zu Mach mich mein Glück ${ }^{3 \mathrm{I}}$ und das Lied Man sing man sag, beide mit dem Akrostichon „Ma-Ri-A Jacobe“. Es wird vermutet, dass diese Lieder im Vorfeld oder Umkreis der Hochzeitsfeierlichkeiten entstanden und sich Senfl auf diesem Wege bei potentiellen Arbeitgebern vorstellen wollte. ${ }^{32}$ Ein Lied, das zwar kein Akrostichon trägt, den Namen "Jacobe“ aber in der letzten Zeile Strophe direkt

28 Das Babst'sche Gesangbuch, Reprint der Ausgabe Leipzig: Valentin Babst 1545, hrsg. von Konrad Ameln, Kassel I929, Nr. I3. Georg von Brandenburg war der Erzieher König Ludwigs II. und spielte wohl eine wichtige Rolle in der Vermittlung lutherischen Gedankenguts an Maria von Ungarn.

29 Sebastian Ochsenkhun, Tabulaturbuch auff die lauten, Heidelberg: Johann Khol I 558 [Brown I $55_{5}$ ], fol. $65^{\mathrm{v}}-66^{\mathrm{r}}$, vertont von Gregor Peschin.

30 Siehe auch Ada Kadenbach, „Das Akrostichon im Kirchenlied. Typologie und Deutungsansätze“, in Jahrbuch für Liturgik und Hymnologie 36 (1996/97), S. I75-207.

3 I In den gedruckten Quellen ist den Sätzen immer der Text „Mag ich mein Glück erwarten nicht" unterlegt, von dem jeweils nur eine Strophe angeführt ist, so dass nicht feststeht, ob auch dieser Text das Akrostichon berücksichtigt.

32 Bente, Neue Wege (wie Anm. 22), S. 304 und 306. 
preisgibt und inhaltlich unverkennbar auf die Hochzeit hinweist, ist Der ehlich Stand ist billich gnant. ${ }^{33}$

Hinsichtlich der Aussage des Liedtextes steht Mag ich Unglück jedoch abseits der anderen an Frauen gewidmeten Lieder Senfls. Der Typus des Namensakrostichons geht im Falle einer weiblichen Adressatin oft mit einem Preislied einher, das etwa die Schönheit, Herkunft und moralische Gesinnung der Empfängerin rühmt. Ein schönes Beispiel dafür aus dem Liedschaffen Senfls ist Aus gutem Grund, das Anna von Ungarn, die Gattin Ferdinands I., anspricht (Senfl, SW II, Nr. 67). Dieses Lied hat sich in einer sehr ausgefallenen Quelle erhalten, die die Funktion eines solchen persönlich adressierten Liedes dokumentiert: Es handelt sich um vier gestickte Stimmbücher, die in der Kunstsammlung auf Schloss Ambras nahe Innsbruck aufbewahrt werden. Die mit schwarzer Seide und Goldfaden gestickten Noten wurden der Hausherrin Anna zusammen mit einem weiteren Stimmbuchsatz für den frisch gekrönten Kaiser Karl V. als kostbares Geschenk wohl in Innsbruck im Jahr I530 überreicht. ${ }^{34}$ Hier verschmelzen Liedtext, ein mehrstimmiger Satz und die Art der Visualisierung zu einem Kunstobjekt, das als Präsent für Aufmerksamkeit sorgte. In dem Lied wird Anna als „Zier der schönen Weiben“ gepriesen:
$A$ us guetem grund, vo[n] stund,
Nacht tag vnd zeit, so weyt, ich sing vnd sag, das khain mensch mag, ich ymmer khan, on abelon, Jr höflich zucht beschreyben, soll ir das lob beschehen, man mues sy lassen pleyben, von wem sy wirt gesehen, ain zier der schönen weyben. der mues ir guots veriehen.

Nit hie allain, ich main, wirt sy gepreißt, Jr güet beweißt, dann sy khan lob eriagen, der gleich bey meinen tagen, vor nie hab hören sagen.

(Text nach D-Mbs Mus.ms. 3I 55 , no. 8 I $\left[\right.$ fol. $\left.\left.87^{\mathrm{v}}-88^{\mathrm{r}}\right]\right)^{35}$

33 Ironischerweise stellt die früheste Quelle dieses für die Hochzeit des erzkatholischen Herzogs komponierten Satzes neben Otts Liedersammlung von I 544 [RISM I $544^{20}$ ] die in Wittenberg gedruckte Anthologie von Georg Rhau, Newe Deudsche Geistliche Gesenge [RISM I $544^{21}$ ] dar. Daneben überliefern die aus der zweiten Hälfte des I6. Jahrhunderts stammenden Quellen D-Usch 236 und Brown I 558 , das Stück.

34 Für eine Reproduktion beider Stimmbuchsätze und Editionen der Stücke siehe Imperiale Musik von Schloß Ambras aus der Regierungszeit Karls V. und Ferdinands I., hrsg. von Walter Salmen, Innsbruck 1992. Eine weitere Kontextualisierung des Geschenks unternahm Birgit Lodes in einem Vortrag auf dem IMS Kongress in Zürich 2007. Ein Beitrag der Autorin zu gestickten Stimmbüchern wird in den Senfl-Studien 2 erscheinen.

35 Hervorhebung des Akrostichons hier wie in den folgenden Liedtexten von der Autorin. 
Die Zusammenstellung aller erhaltenen Liedsätze Senfls mit weiblichem Namensakrostichon in Anhang I zeigt, dass die inhaltlichen Aussagen in den meisten Fällen keine großen Abweichungen aufweisen. Aus den üblicherweise sehr allgemein gehaltenen Liedtexten kann man in einigen Fällen herauslesen, dass es sich noch um Werbungslieder handelt oder dass die beschriebene Situation bereits auf eine Hochzeit verweist, während in anderen die Angeredete in ihren Tugenden von einem „Ich“ besungen wird und sich in seltenen Fällen auch ein Dialog entspinnt. Mag ich Unglück kann keiner dieser Gruppen zugeordnet werden und stellt in keiner Weise ein Preislied dar. Hier werden die Worte auch nicht einem Mann in den Mund gelegt, es scheint einzig die im Akrostichon Genannte zu Wort zu kommen. Lediglich in der dritten Strophe wird mit „meinem Herrn" eine weitere Person indirekt angesprochen; es geht allerdings aus dem Text nicht eindeutig hervor, ob damit gemeint ist, dass sie sich ihrem Ehemann oder gegenüber Gott willig ergeben will. In Forsters Überlieferung, die in textlichen Belangen allerdings unzuverlässig scheint, heißt es in der dritten Strophe sogar: „Glück zu auf meiner Seiten“. Im Falle eines an eine Verlobte oder frisch Vermählte dedizierten Liedes wäre doch eher ein „unser Seiten“ zu erwarten. ${ }^{36}$ Der Anlass der Komposition und vielleicht auch ein möglicher Auftraggeber scheinen hier einer anderen Konstellation zu entsprechen, als es bei den meisten Akrostichonliedern mit weiblichem Namen der Fall ist, in denen der Mann stets seine Geliebte oder (zukünftige) Gattin anspricht.

\section{KÖNIG UND KÖNIGIN VON UNGARN IM LIED 2}

Ein weiteres Akrostichonlied von Senfl, das mit Maria von Ungarn in Verbindung gebracht wird, ist Lust mag mein Herz (Senfl, SW II, Nr. 8). Es trägt ein Doppelakrostichon mit den ineinander verwobenen Namen „Ludwig“ und „Maria“:

36 Diese von Forster überlieferte Textvariante ist einmalig, wie er in der 2. Strophe, 6. Zeile abweichend von den anderen Textzeugen auch ,jr vntrew vnd finantzen“ anstatt „schalckheit vnd finantzen“ abdruckt. In D-HEu Cod. Pal. germ. 343, no. I 74 (fol. I $\left.26^{\mathrm{r}-\mathrm{v}}\right)$ und der Flugschrift von G. Wachter lautet die Schlusszeile wie auch in der geistlichen LiedblattFassung tatsächlich „,auf unser Seiten“. Die erstgenannte Lieder-Handschrift, die keine musikalische Notation enthält, entstand nach I 547 (siehe Matthias Miller und Karin Zimmermann, Die Codices Palatini germanici in der Universitätsbibliothek Heidelberg (Cod. Pal. germ. 304495), Wiesbaden 2007 [Kataloge der Universitätsbibliothek Heidelberg VIII], S. I67-I77; auch online unter http://www.ub.uni-heidelberg.de/archiv/8470 einsehbar) und gibt einen in Einzelheiten von den anderen Textzeugen abweichenden Text. Obwohl diese Fassung in einigen Wendungen schlüssiger als etwa Forster erscheint, wurden hier doch offensichtlich Eingriffe vorgenommen. Den Textglättungen fiel etwa das Akrostichon zum Opfer, das in D-HEu Cod. Pal. germ. 434 ein unkenntliches „Marea“ ergibt. 
$L U$ st $M A g$ mein Hertz, on schertz, nit haben noch, weÿl doch, mir wider streÿt, die Zeÿt, in Hoffnung beÿt,

bis sich die selb mit frewden geÿt.

Darumb RIcht dich, als ich, des vals erwart, vngspart, finst du an mir, was dir, aus hertzen gir, gefellig ist gwer ich dich schir

WIG All sach ring, kain ding, las kümern dich, wirt sich verkeren baldt, vil gwaldt, in andre gstaldt,

glück dir vnd mir dann vorbehaldt.

(Text nach D-Mu $8^{\circ}$ Cod. ms. 328, fol. $27^{\mathrm{r}}$ )

Als Anlass- und Entstehungszeit für dieses Lied wurden sowohl die Wiener Doppeleheschließung I5 I5 als auch die tatsächliche Hochzeit Ludwigs und Marias im Januar I 522 vorgeschlagen. ${ }^{37}$ Aber auch dieses Lied fügt sich nicht ohne weiteres in die Reihe der Hochzeitslieder Senfls, etwa das bereits erwähnte Der ehlich Stand. Wie in Mag ich Unglück ist die Klage über die Gegenwart vorherrschend und das Glück allein der Zukunft vorbehalten. Zwar spricht das „Ich“ eine weitere Person an und in der 2. Strophe wird eine mögliche Zweisamkeit angedeutet, die Andeutung erscheint aber sehr unverbindlich und nicht besonders werbend in der Wortwahl. Allein der Ausblick in die glücklichere Zukunft scheint beide Personen zu verbinden. Auch die musikalische Ausgestaltung in Senfls Satz verträgt sich nicht mit dem Gedanken eines repräsentativen Geschenks. Es handelt sich um einen sehr kurzen und erstaunlich einfach gestalte-

37 Das Datum I5I5 wird in Walter Senn, „Maximilian und die Musik“, in Ausstellung Maximilian I. Innsbruck [...], hrsg. von Erich Egg, Innsbruck I969, S. 73-85, hier S. 80 vorgeschlagen. Überzeugender scheint mir die Argumentation für I 522: In der Quelle CH-Bu F X I-4 ist das Lied im Tenorstimmbuch mit dem Datum I 522 und einer griechischen Beischrift aufgezeichnet: 15.JW.22 / O $\psi \mathrm{H \lambda} \theta \mathrm{O}$ / Jann Obseus Vindelic[us]. John Kmetz liest die griechische Inschrift als "Ich kam zu spät" und interpretiert, dass Jan Wüst, der Schreiber der Handschrift, zur Hochzeit geladen war, aber nicht rechtzeitig in Buda ankam; siehe John Kmetz, The Sixteenth-Century Basel Songbooks. Origins, Contents, Contexts, Bern u.a. I995 (Publikationen der Schweizerischen Musikforschenden Gesellschaft II, 35), S. 40-42. 
ten Satz. ${ }^{38}$ Betrachtet man allein die Tenorstimme, so findet die Melodie nach einer unverdächtig gestalteten Anfangszeile und einem aufsteigenden kurzen Einwurf in den Mensuren 9-I2 zu einem melodischen Modell, nach dem auf zwei unterschiedlichen Tonhöhen sequenziert der restliche Text vorgetragen wird; die letzte Zeile erfährt dabei textbedingt eine Erweiterung. In rhythmischer Hinsicht gleicht dieses Modell sogar der ersten Zeile, die in melodischer Sicht allerdings einen stufenweisen Aufstieg darstellt, während die Melodie in den letzten Zeilen stets stufenweise abfällt. Stellt man diese musikalische Struktur der textlichen gegenüber, so könnte man beinahe behaupten, dass die Melodie die Textstruktur auf den Kopf stellt. Denn während in der musikalischen Form dem Beginn eine dreifache Wiederholung folgt, sind im Text dagegen Metrum und Reim der ersten drei Zeilen völlig ident und der angehängte Schluss fällt nun aus diesem Schema heraus.

Der vierstimmige Satz ist zu Beginn eher blockhaft gestaltet, und nach der ersten Zeile stockt der musikalische Fluss bereits mit einer Pause in allen Stimmen. Auch der anschließende Einwurf ist noch akkordisch gehalten, dann bringen die Außenstimmen mit Läufen in kleineren Notenwerten Bewegung in den Satz und überspielen immer stärker die vom Tenor vorgegebenen Zeilengrenzen. Auch wenn der Satz in Details mit Witz ausgestattet ist, erscheint es nur schwer vorstellbar, dass sich Senfl, auf der Suche nach einer Anstellung, ausgerechnet mit diesem Stück am ungarischen Hof als Komponist hätte empfehlen wollen.

38 Eine mögliche Erklärung für die Kürze des Satzes ließe sich allein darin suchen, dass er - wie etwa Aus gutem Grund - für eine Darbietung in besonderer Gestalt gedacht war. Also etwa zusammen mit einem anderen Stück auf Leinen gestickt oder vielleicht auf eine Tischplatte eingelegt oder geätzt und in diesem Fall einfach nur wenig Platz zur Verfügung stand. Es würde sich dann um eine „maßgeschneiderte“ Komposition handeln. 

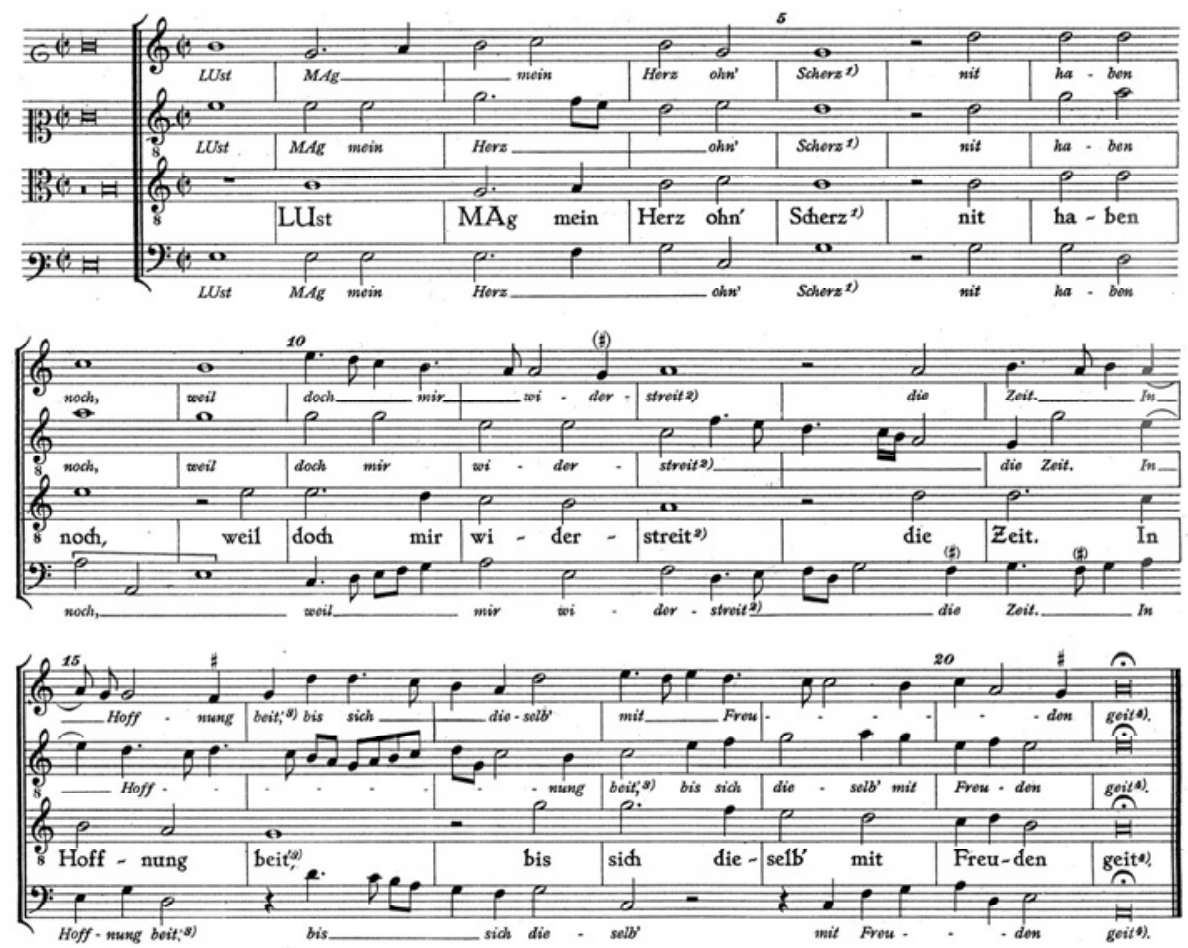

Notenbsp. I : Ludwig Senfl, Lust mag mein Herz. Senfl, SW II, Nr. 8

$\mathrm{Zu}$ Mag ich Unglück und Lust mag mein Herz gesellt sich noch ein drittes Lied in den Kreis der mehrstimmig vertonten ungarischen Königslieder, das zwar nicht für Maria, aber für ihren Gatten Ludwig II. von Ungarn geschrieben wurde: König ein Herr ob allem Reich. Dieses Lied enthält ebenfalls ein Namensakrostichon: In den drei Strophenanfängen verbergen sich die Worte „KVNIG LVDWIG“. Zu diesem Lied ist eine vierstimmige Vertonung von Thomas Stoltzer erhalten, der mit einem Schreiben vom 8. Mai I 522 nach Buda in den Dienst Marias von Ungarn berufen wurde. Stoltzer war aber möglicherweise bereits bei der Hochzeit von Maria und Ludwig anwesend. ${ }^{39}$ 
Liebe, Tod und Glaubensfragen als Komponenten einer Lied-Karriere im I6. Jahrhundert

KVNIG ein herr ob allem reych,

wie gar vngleych,

mein sach yetz steet,

nicht für sich geet,

was jch anfach,

mer vngemach,

an allem ort sich nun erzeigt,

die zeit sich neigt,

zu bösem end,

woes Got nicht wendt,

dem traw jch doch,

er lebt ye noch,

jch hoff er schicks noch als zu gut,

hab starcken mut,

die seynen Got nit verlassen thut.

$L V D$ doch vormals auch vnglück fast,

sein schweren last,

auff manchen man,

den als jhr than,

verhindert ist,

durch vnfals list,

auß den hinach seyn worden leut,

von den man heut,

noch singt vnd sagt,

was ehr eriagt,

sie hand durch rath,

vnd manlich that,

regieret wol jr leut vnd landt,

darinn erkant,

ist gwaltigklich die Gottes handt.

WIG drumb dergleich mein thun also,

Got weiß wol wo,

hinauß es wil,

mir ists zuuil,

vnd vber meyn witz,

so gibt es yetz,

auch andern vil zu schaffen gnug,

sey eyner halt klug,

jm dannoch zerrint,

die welt ist gschwind,

jch nym die zeyt,

wie sie Got geyt,

seyn will geschech in aller welt,

wies jm gefellt,

dahin hab jch mein sach gestelt.

(Flugschrift, Zwey newe lieder, Das Erste, Künig ein herr ob allem reych,

Nürnberg: Georg Wachter o.J. $)^{40}$

40 In der zweiten Quelle, die diesen Text dem mehrstimmigen Satz unterlegt mitteilt (RISM I $544^{20}$, Nr. 65), weicht der Text meist nur in der Schreibung ab. Der einzige Unterschied ist in der 2. Strophe, 4. Zeile zu finden. Statt „den als jhr than“ heißt es dort „denn als jr schön“ (was allerdings den Reim auf „man“ bzw. „Mann“ nicht einlöst). 
Neben der singulären Überlieferung des Satzes von Stoltzer in der Liedersammlung von Hans Ott I 544 ist der Text auch in einer Flugschrift überliefert ${ }^{41}$ wo das Lied mit zwei weiteren kombiniert ist. Auf der Titelseite des Druckes ist neben einem Holzschnitt folgende Beschreibung zu lesen: Zwey newe lieder, Das Erste, Künig ein herr ob allem reych. Das ander, Mag jch vnglück nit widerstan, gut hoffnung han. Noch ein ander Lied, Gut Reyter bey dem weyne saß. Bei dem an zweiter Stelle genannten Lied handelt es sich um die weltliche Version von Mag ich Unglück. Die Zusammenstellung von Ludwigs Lied mit Mag ich Unglück in der weltlichen Version könnte ein Hinweis darauf sein, dass bereits diese doch bereits auf Maria bezogen wurde. Die Formulierung des Titels macht deutlich, dass es sich nicht um einen Druck dreier wahllos kombinierter Lieder handelt, sondern um ein - inhaltlich begründetes - Liedpaar (Künig ein Herr und Mag ich Unglück), dem ein weiteres Lied folgt. Der Konnex des Liedpaares besteht eben offensichtlich darin, dass hier das Lied des Königs von Ungarn, Ludwig, mit dem der Königin Maria kombiniert erscheint. Das dritte Lied Gut Reyter bey dem weyne sa $\beta^{42}$ ist ein spöttisch moralisierendes Lied, das von einem (wohl mehrdeutig zu verstehenden) Reiter handelt, der in der Trinkstube mit seiner Gewissenlosigkeit gegenüber seiner Geliebten prahlt. Diese hört jedoch die verletzenden Worte und weist ihn in den folgenden Dialogstrophen vor ihrer Tür ab. Eine Bezugnahme auf das vorstehende Liedpaar ist in diesem Fall nicht zu erkennen. Vielleicht wurde dieses Lied der Flugschrift aus rein verkaufsorientierten Überlegungen hinzugefügt: Der ernsten moralisierenden Tendenz der zwei Herrscherlieder wird mit einem pikant vergnüglichen Lied ein Gegenpol gesetzt und dem potentiellen Käufer des Drucks somit eine abwechslungsreiche Publikation geboten.

4I Hans Ott (Hrsg.), Hundert vnd fünfftzehen guter newer Liedlein, Nürnberg: [Johann vom Berg und Ulrich Neuber] I 544 [RISM I $544^{20}$ ], Nr. 65; Zwey newe lieder, Das Erste, Künig ein herr ob allem reych, Nürnberg: Georg Wachter o.J. [nicht in VDi6]. Zwei erhaltene Exemplare sind derzeit bekannt: I-Rvat Stamp. Pal. VI 54.75 und GB-Lbl General Reference Collection I I522.df. I 5. Ich danke Michael Fischer vom Deutschen Volksliedwerk Freiburg für diese Auskunft.

42 Erk/Böhme, Liederhort (wie Anm. I I), Bd. 3, Nr. I3O2. 


\section{Yopey newdieoer/Dogs Erfe/zänig cin bert ob allem reych.}

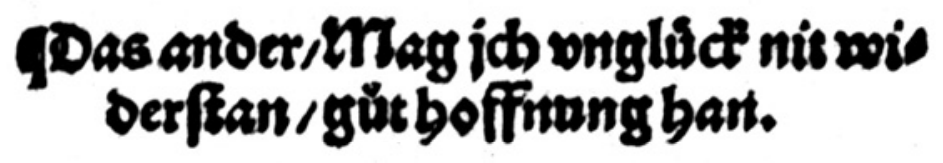

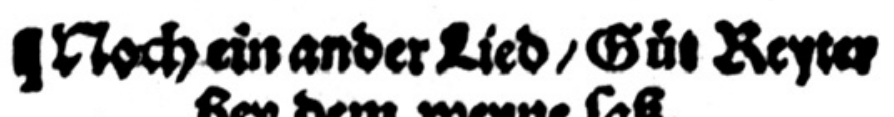
Bey bem reyne fap.

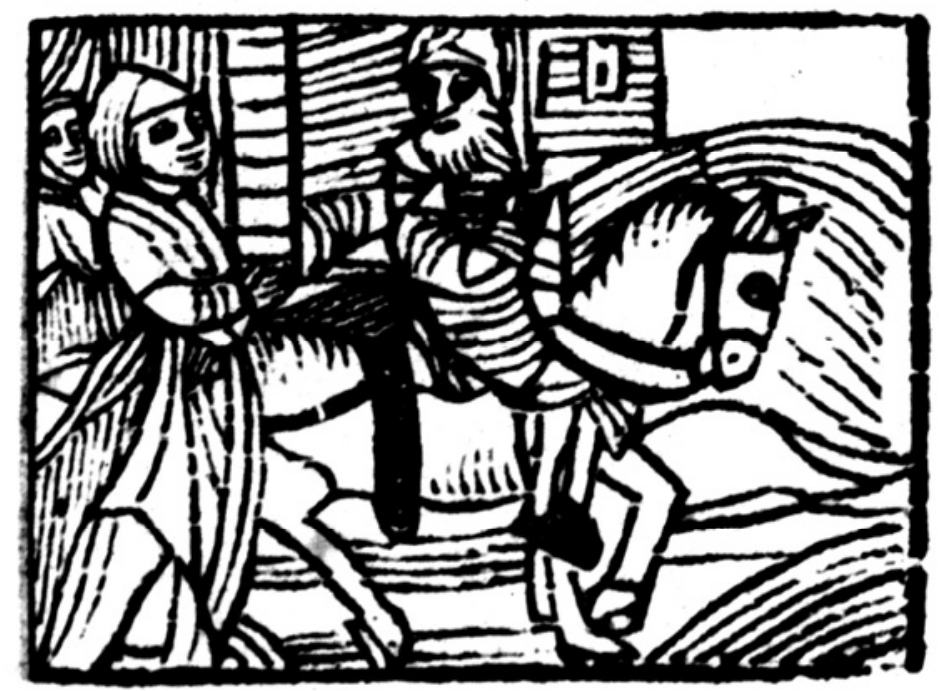

Abbildung I: Titelblatt der Flugschrift Zwey newe lieder, Das Erste, Künig ein herr ob allem reych, Nürnberg: Georg Wachter o.J. (I-Rvat Stamp. Pal. VI 54.75)

Die in Nürnberg gedruckte Flugschrift trägt keine Datierung, so dass in der Literatur häufig mit Wackernagel ein aus dem Liedinhalt geschlossenes Datum „um I 525 “ angenommen wurde: ${ }^{43} \mathrm{Da}$ in Ludwigs Lied keinerlei Hinweis auf Mohács gegeben ist, müsse der Druck vor der Schlacht entstanden sein. Diese Folgerung trifft wohl auf das Entstehungsdatum des Liedes selbst $\mathrm{zu}-$ es wird 
auch von der Vertonung durch Stoltzer, der ebenfalls I 526 stirbt, gestützt -, nicht aber auf das des Drucks. Hier kann bereits der Holzschnitt auf der Titelseite weitere Hinweise liefern (siehe Abb. I). Am linken Bildrand sind zwei Frauen dargestellt, von denen diejenige im Hintergrund etwas kleiner erscheint und von der im Vordergrund Stehenden großteils verdeckt wird. Das suggeriert, dass es sich um eine Dame mit ihrer Dienerin handeln könnte. Die restlichen drei Viertel des Bildes nimmt neben angedeuteter Landschaft und Architektur ein Reiter auf einem Pferd ein, der sich von den Frauen wegzubewegen scheint, sich aber im Abschied noch einmal zu ihnen umwendet. Diese Abschiedsszene in Verbindung mit den beiden auf den folgenden Seiten abgedruckten Akrostichonliedern scheint eindeutig auf Ludwigs Abschied vor der Schlacht von Mohács zu rekurrieren, wie er in der 4. Strophe von Ach Gott was soll ich singen beschrieben ist:

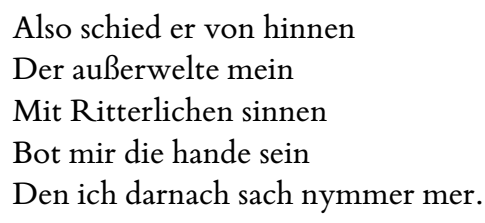

Obwohl diese Ereignisse - der Abschied, die Schlacht - in den beiden Liedtexten nicht angesprochen werden, scheinen sie doch bereits mit dem königlichen Paar verbunden zu sein und der Titelholzschnitt bildet dazu eine optische Erinnerungsbrücke. Das Motiv des Holzschnitts ist allerdings nicht neu, es handelte sich ursprünglich um eine Volksbuch-Illustration zum Heldenepos Sigenot, das von Ambrosius Huber um I 500 in Nürnberg gedruckt wurde. Zwar ist von dieser Ausgabe kein Exemplar erhalten geblieben, aufgrund der Wiederverwertung der Holzschnitte für Liedheftchen ist jedoch ein Fragment der IllustrationsSerie von Frieder Schanze rekonstruiert worden. ${ }^{44}$ Auch in der Offizin von Kunigunde Hergotin und Georg Wachter entstand um I530 eine heute ebenfalls nicht erhaltene Ausgabe des Sigenot, für die die Illustrationen aus Ambrosius Hubers Druck nachgeschnitten wurden. ${ }^{45}$ Das für die Lieder des ungarischen Königspaares gewählte Motiv stellte im Kontext des Sigenot den Abschied Hildebrands dar, der von der Herzogin Abschied nimmt, um in den Kampf gegen den Riesen Sigenot zu ziehen, der Dietrich von Bern gefangen hält. In den

Frieder Schanze, „Volksbuch'-Illustrationen in sekundärer Verwendung“, in Archiv für Geschichte des Buchwesens 26 (I986), S. 239-257, hier Nr. 3.I., S. $25 \mathrm{I}-253$ (Abb. 20 gibt die Vorlage des Wachter'schen Titelholzschnitts wieder).

45 Ebda., S. 250 und Nr. 3.3, S. 253 f. Schanze war zum Zeitpunkt des Aufsatzes der Lieddruck der ungarischen Königslieder, der ebenso in diese Serie einzureihen ist, noch nicht bekannt. Mein Dank gilt Stephanie Moisi (Graz), die mir diesen Literaturhinweis und weitere wertvolle Informationen zukommen ließ. 
Grundzügen gleicht sich also das Erzählte: ein tapferer Ritter nimmt Abschied von seiner Gattin, da er sich um seiner Ehre willen in einen gefährlichen Kampf begeben muss. ${ }^{46}$ Die Auswahl des Bildmotivs wurde demnach sorgfältig und nicht ohne Hintergrundwissen vorgenommen.

Dass die Liedflugschrift tatsächlich erst nach der Schlacht von Mohács entstand, stützt der Druckervermerk auf der letzten Seite des Liedheftchens: „Gedruckt zu Nürnberg durch Georg Wachter“. Wachter heiratete Ende I 527 die Witwe Kunigunde Hergotin und erst ab I 528 erschienen in deren Offizin auch Drucke unter dem Namen Georg Wachter. ${ }^{47}$ Als terminus ante quem ist der Tod Wachters im Jahre I $547 \mathrm{zu}$ setzen. Eine genauere Datierung des Drucks scheint dagegen nicht möglich, da auch die bekannten Überlieferungskontexte keine weiteren Hinweise liefern. ${ }^{48}$ Die in den Bibliothekskatalogen der erhaltenen Exemplare vorgeschlagenen Daten I 540 bzw. ca. I 545 erscheinen aber recht spät angesetzt. ${ }^{49}$ Trotzdem kann somit der Druck nur ein Zeugnis dafür sein, dass zumindest in späteren Zeiten, möglicherweise als Rückschluss von der geistlichen Kontrafaktur auf das weltliche Vorbild, auch der weltliche Liedtext tatsächlich auf Maria von Ungarn bezogen wurde.

Auffallend ist dennoch, dass auch das Lied König ein Herr ob allem Reich, wie bereits Mag ich Unglück und Lust mag mein Herz inhaltlich ganz von der Klage über die Schlechtigkeit des jetzigen Zustands dominiert ist, und mit dem Vertrauen auf Gott große Hoffnungen in die Zukunft gesetzt werden. Die drei Lieder sind auch in ihren mehrstimmigen Vertonungen mit ähnlichen Merkmalen ausgestattet. Sie sind alle im selben Modus, nach Glarean dem Hypoäolischen, angelegt, was vielleicht durch die gemeinsame Grundstimmung bedingt sein könnte. Mag ich Unglück entspricht mit einem akkordisch dominierten Beginn und einem bewegteren, stärker polyphon geprägten Abgesang dem Aufbau

46 Damit ist es auch ausgeschlossen, dass sich die Illustration auf den Reiter des dritten Liedes beziehen könnte, der von der Geliebten nicht verabschiedet, sondern von der Tür gewiesen wird.

47 Christoph Reske, Die Buchdrucker des 16. und 17. Jahrhunderts im deutschen Sprachgebiet, Wiesbaden 2007 (Beiträge zum Buch- und Bibliothekswesen 5I), S. 67If.

48 Das heute im Vatikan befindliche Exemplar wurde in einen Lieddruck-Sammelband aus dem Besitz des Kurfürsten Ludwig VI. von der Pfalz aufgenommen. Der jüngste Druck dieser Sammlung entstand I 564 und der heutige Einband ist erst in Rom angefertigt worden; siehe Frieder Schanze, „Privatliederbücher im Zeitalter der Druckkunst. Zu einigen LieddruckSammelbänden des I6. Jahrhunderts", in Gattungen und Formen des europäischen Liedes vom 14. bis zum 16. Jahrhundert, hrsg. von Michael Zywietz, Volker Honemann und Christian Bettels, Münster 2005 (Studien und Texte zum Mittelalter und zur frühen Neuzeit 8), S. 203-242, hier S. 232-239 (Nr. I3). Für diesen Hinweis danke ich erneut Stephanie Moisi.

49 Online Katalog der British Library und Elmar Mittler (Hrsg.), Bibliotheca Palatina: Katalog und Register zu Mikrofiche-Ausgabe Druckschriften der „Bibliotheca Palatina“, 4 Bde., München I999, Bd. 2, S. I032, Nr. I I995. 

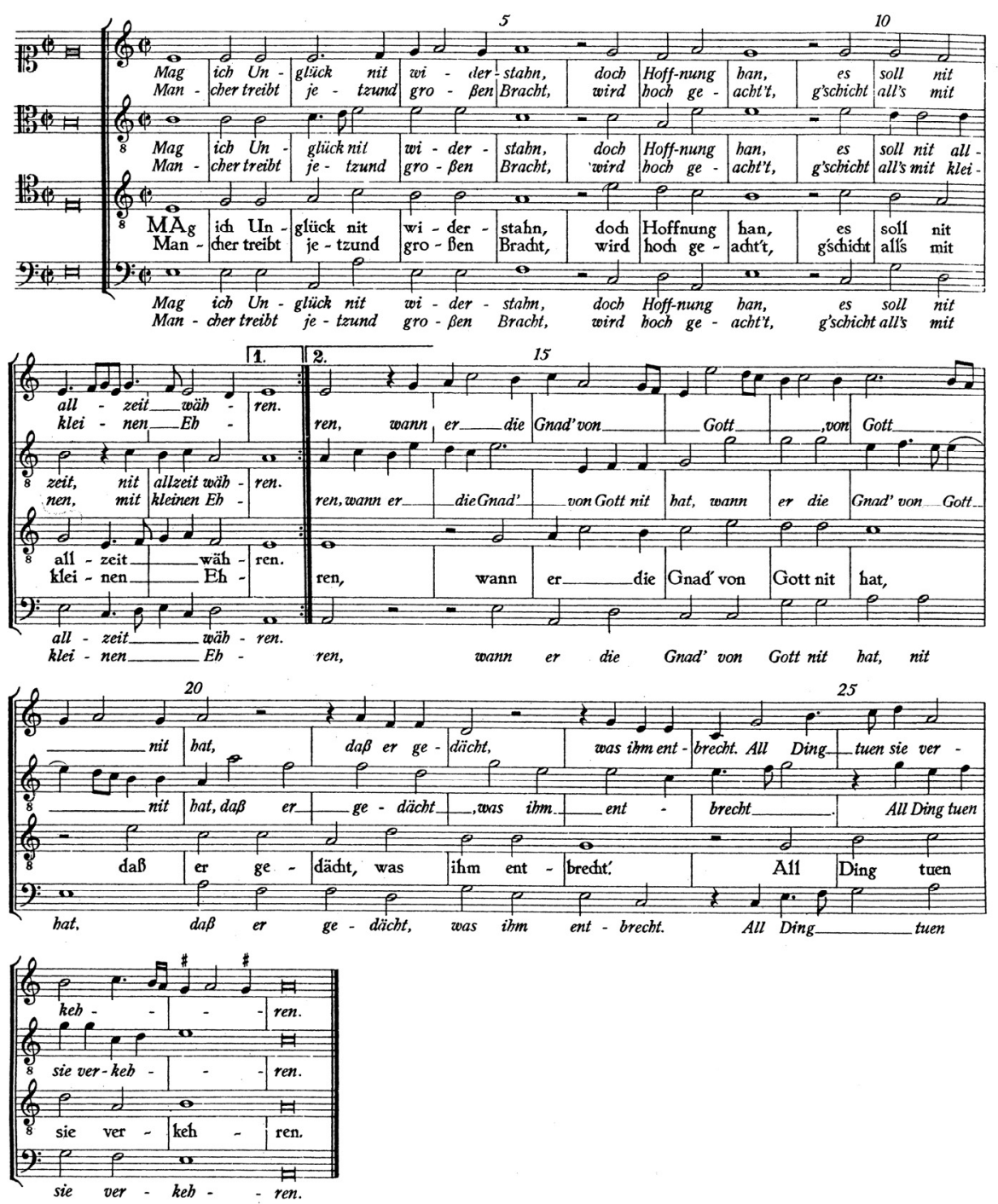

Notenbsp. 2: Ludwig Senfl, Mag ich Unglück nit widerstan. Senfl, SW V, Nr. I3 
Liebe, Tod und Glaubensfragen als Komponenten einer Lied-Karriere im I6. Jahrhundert
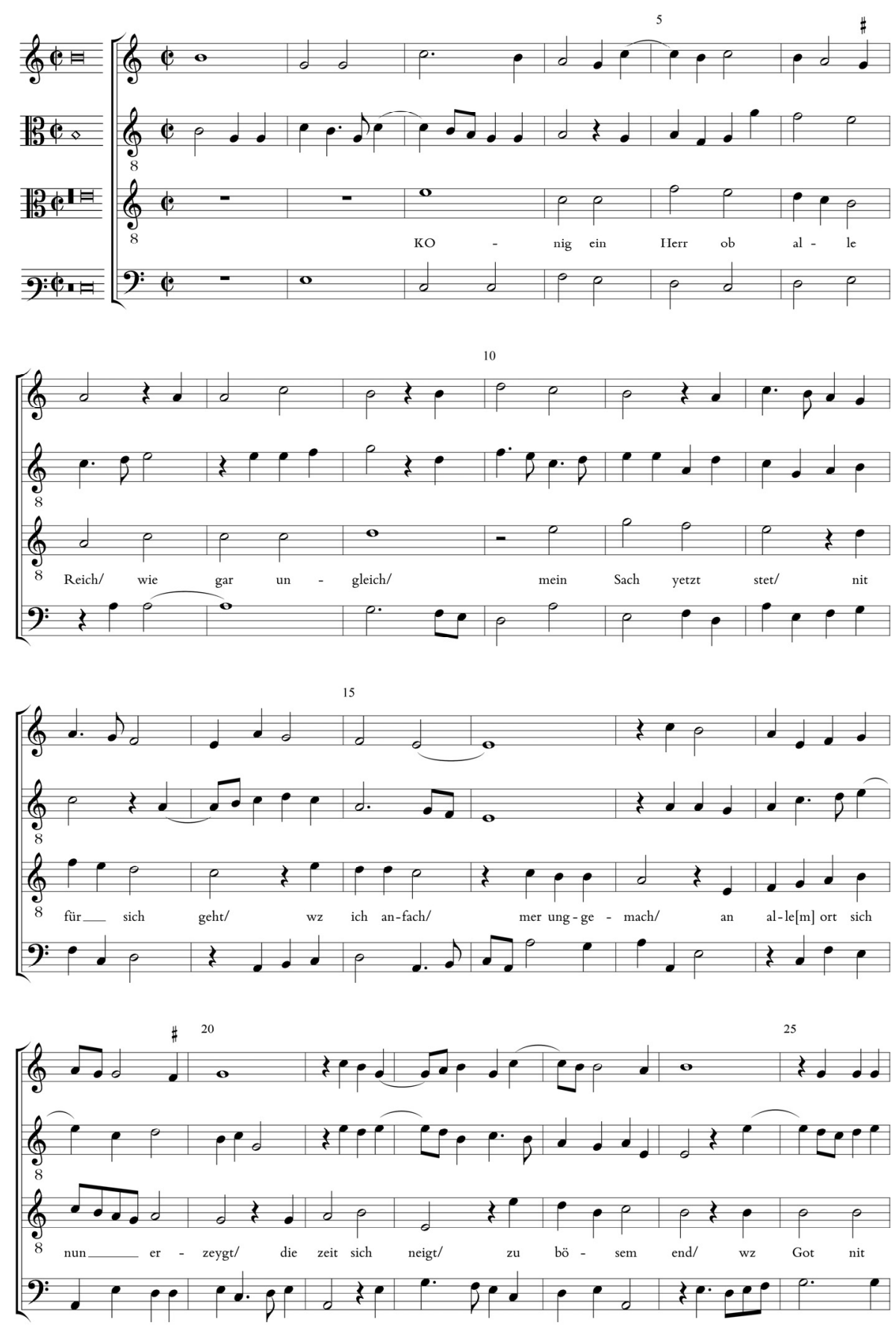

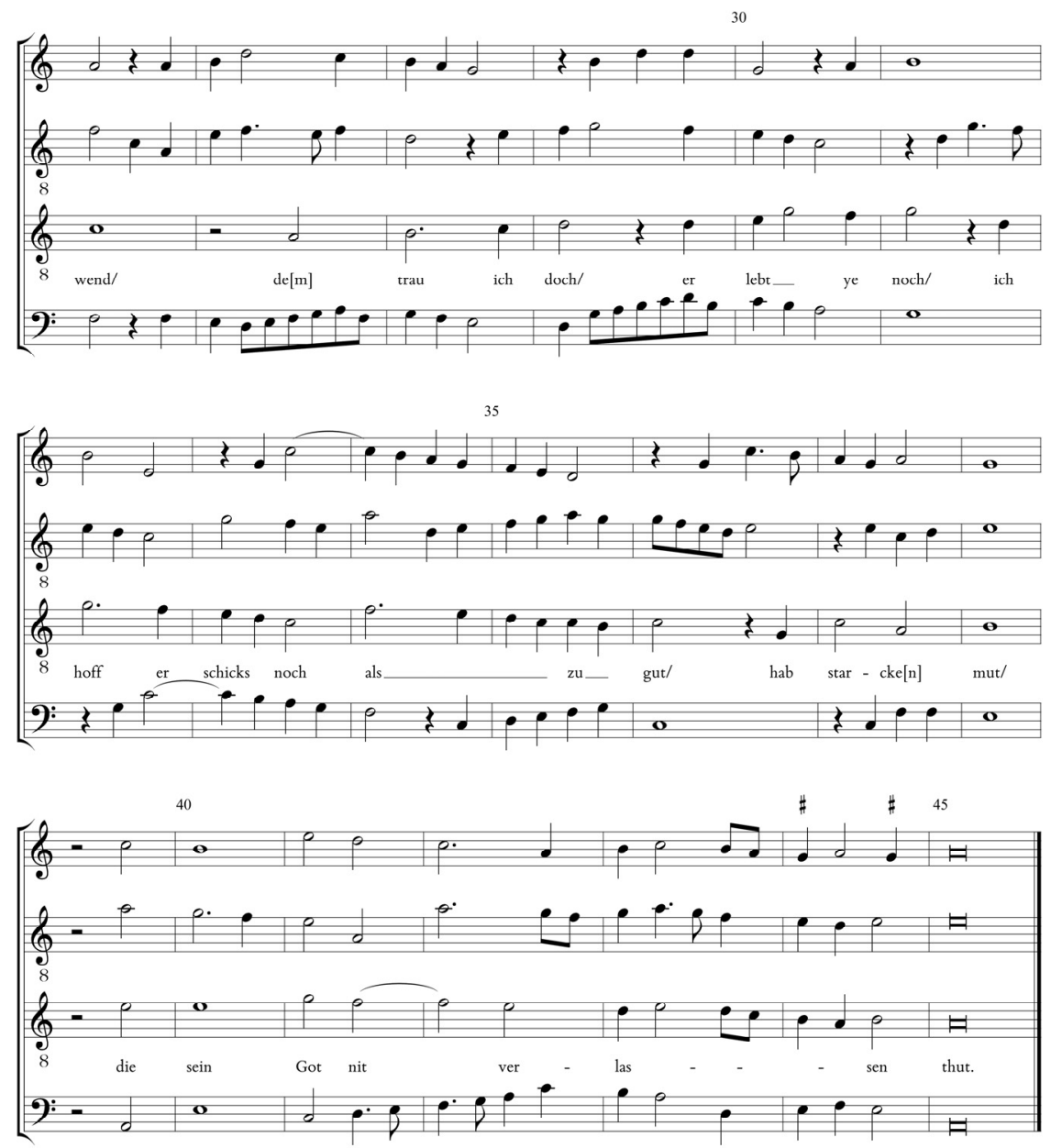

Notenbsp. 3: Thomas Stoltzer, König ein Herr ob allem Reich. RISM I $544^{20}, \mathrm{Nr} .65$

von Lust mag mein Herz. Allerdings ist Mag ich Unglück das einzige der drei Lieder, das in Kanzonenform - der üblichen „Hofweisenform“ - angelegt ist, obwohl doch der Inhalt wie festgestellt keineswegs dem eines Werbungsliedes entspricht. Mit Lust mag mein Herz teilt das Lied weiterhin die Häufung von Sequenzbildungen. Waren diese im ersten Fall jedoch allein auf die Tenorstimme beschränkt, so durchzieht diese Technik im Schlussteil von Mag ich Unglück darüber hinaus den gesamten Satz (M. I9-24). Alle Stimmen verwenden hier auf unterschiedlichen Tonhöhen, zeitlich versetzt und im Diskant auch diminuiert dieselbe schlichte 4-tönige Figur. 
König ein Herr ob allem Reich (siehe Nbsp. 3) unterscheidet sich von den beiden anderen Liedsätzen darin, dass es mit einer Vorimitation in allen Stimmen (dabei in der Altstimme mit verkürzten Notenwerten) beginnt. Auch hier beschränken sich die sequenzierten Figuren zunächst auf die Tenorstimme (M. IO-I6) und breiten sich erst gegen Ende auf alle Stimmen aus (M. 3I-38), wobei in diesem Fall die Konstruktion nicht so strikt und gedrängt konzipiert ist. König ein Herr ist mit 45 Mensuren allerdings auch eindeutig der umfangreichste der drei Sätze. Die Heraushebung einer Textzeile mit einer eigenen musikalischen Behandlung, die in Lust mag mein Herz und Mag ich Unglück zu Beginn des Satzes auftrat, ist nun der letzten Zeile vorbehalten. Eine Pause in allen Stimmen in Mensur 39 stoppt den musikalischen Fluss, und die letzte Zeile wird im homophonen Satz wie eine Sentenz vorgetragen, in der ersten Strophe: „die sein Got nit verlassen thut“. Wiederum allen drei Sätzen gemein ist das eindeutige Vorherrschen von stufenweise absteigenden Motiven gegenüber Figuren mit Aufwärtsbewegung in der Tenorstimme. Wie bereits die Moduswahl könnte natürlich auch diese Übereinstimmung aus dem gemeinsamen Klagetopos der Liedtexte resultieren.

Nimmt man nun an, dass alle drei Lieder tatsächlich dem Königspaar gewidmet waren und begibt sich auf die Suche nach einem möglichen Entstehungsszenario, so erscheint es mir nicht länger sinnvoll, ausschließlich die Hochzeit des Paares als Anlass ins Auge zu fassen. Die in den Liedtexten vermittelten Inhalte wollen sich in diesen Rahmen nicht recht einfügen. Vielmehr wäre es vorstellbar, dass noch Jahre vor der Hochzeit etwa Maximilian I., der sich um das Wohl der beiden zukünftigen Königinnen Maria und Anna sorgte, als Initiator von solchen Liedgaben in Frage käme. Die beiden reginulae wurden nach dem Fürstenkongress I5IS in Wien seit März ISI7 gemeinsam im „Frauenzimmer“ in Innsbruck erzogen und der Neustifter Chronist Georg Kirchmair berichtet: „Vnd an Zweifl, als wol vermergkht, ward den baiden Kunigin die Zeit genueg lang zu Innsprugg ...". ${ }^{50}$ Maximilian konnte nur selten persönlich seine Enkelin und die zukünftige Gattin seines Enkels besuchen. Es ist aber belegt, dass er sie auch in seiner Abwesenheit nicht aus den Augen verlor. So schickte er ihnen etwa im Sommer I5I7 einen Gemsenjäger, der sie mit den Vergnügungen der Jagd - zeitlebens eine der Lieblingsbeschäftigungen Marias - vertraut machte. Trotz seiner stets prekären finanziellen Situation machte Maximilian den beiden Königinnen auch kostbare Geschenke wie etwa juwelengezierte Samthüte. ${ }^{5 I}$ Weshalb hätte er also nicht auch seinen damaligen Hofkomponisten Ludwig Senfl damit beauftragen sollen, für die musikbegeisterte Maria einen mit

50 Zitiert nach „Georg Kirchmair’s Denkwürdigkeiten“, hrsg. von Theodor Georg Karajan, in Fontes Rerum Austriacarum I. Scriptores, I. Bd. (I855), S. 4I 8-534, hier S. 45 I.

5I Tamussino, Maria von Ungarn (wie Anm. 4), S. 48. 
Akrostichon ausgestatteten Text zu vertonen und mehrstimmig zu setzen? Die Zeit in Innsbruck nahm Maria möglicherweise tatsächlich als eine unangenehme Wartezeit, wie sie der Liedtext widerspiegelt, wahr. Vielleicht fühlte sie sich auch in einer Art Konkurrenzverhältnis zu Anna, die von Besuchern als fröhlich und mit einem Teint wie Milch und Blut geschildert wird, wogegen die Beschreibung Marias weniger vorteilhaft ausfällt: nicht sehr hübsch und mager. Dafür finden schon in dieser Zeit ihre Intelligenz und ihr großer Verstand Bewunderung. ${ }^{52}$ Maria könnte etwa die beiden von Senfl vertonten Lieder mit sich nach Ungarn genommen und dort nach der Hochzeit ein Lied nach diesem Vorbild für ihren Gemahl bei Stoltzer in Auftrag gegeben haben. Unter Umständen förderte sie sogar selbst nach Ludwigs Tod die Verbreitung von König ein Herr ob allem Reich, wie sie auch noch als Statthalterin der Niederlande Portrait-Kopien von dem Verstorbenen anfertigen ließ, um einerseits sein Andenken, gleichzeitig aber auch ihren Anspruch auf den Titel der Königin von Ungarn zu bewahren. ${ }^{53}$

\section{GLAUBENSFRAGEN - DAS GEISTLICHE LIED MAG ICH UNGLÜCK NIT WI- DERSTAN}

Eindeutig ist die Verbindung von Mag ich Unglück mit Maria von Ungarn in der geistlichen Textfassung gegeben. Eine Zuschreibung in der Art von „Der Durchleuchtigsten Großmechtigen Fürstin, Frawen Frawen Maria, zu U[ngarn] vnd $\mathrm{B}[\mathrm{öhmen}]$ etc. Kü[nigin] geborne Ertzherzogin zu Osterreich etc. New gaystlich Lied" findet sich erstmals auf einem Liedflugblatt ohne Erscheinungsdatum, das aber den Indizien zufolge um I 529 entstand (siehe Abb. 2). ${ }^{54}$ Den ersten datierten Beisatz dieser Art, hier "dorch de Förstinnen tho Ungern“, 55 bietet das Magdeburger Gesangbuch von I534: Geystlike leder/ vppet nye gebetert tho Wittemberch/dorch D. Martin. Luther., Magdeburg: Hans Walther I $5344^{.6}$

52 Ebda., S. 49.

53 Kurt Löcher, „Hans Krell - Court Painter fo King Louis II of Hungary and his Consort, Mary of Hungary“, in Mary of Hungary. The Queen and Her court 1521-1531, Budapest 2005, S. 69-78, hier S. 77.

54 Der Einblattdruck war Teil eines Lieddruck-Sammelbandes der Hessischen Landes- und Hochschulbibliothek Darmstadt (Sign.: E 4360), der während des 2. Weltkrieges zerstört wurde. In diesem Sammelband waren ausschließlich Drucke der Augsburger Werkstatt Heinrich Steiner aus dem Jahr I 529 gebunden. Siehe Frieder Schanze, „Privatliederbücher“ (wie Anm. 48), S. 207 f.

55 Nach Wackernagel, Kirchenlied (wie Anm. 43), Bd. 3, S. I I8f., Nr. I 56.

56 Zur weiteren Verbreitung der Zuschreibung in Gesangbüchern siehe Albrecht Classen, ,Mein Seel fang an zu singen'. Religiöse Frauenlieder des 15.-16. Jahrhunderts. Kritische Studien und Textedition, Leuven u.a. 2002 (Studies in Spirituality, Supplement 6), S. 270. 


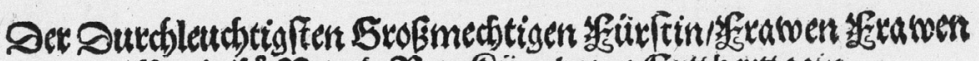

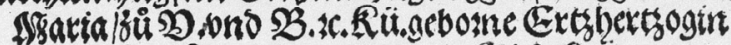

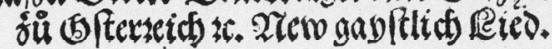
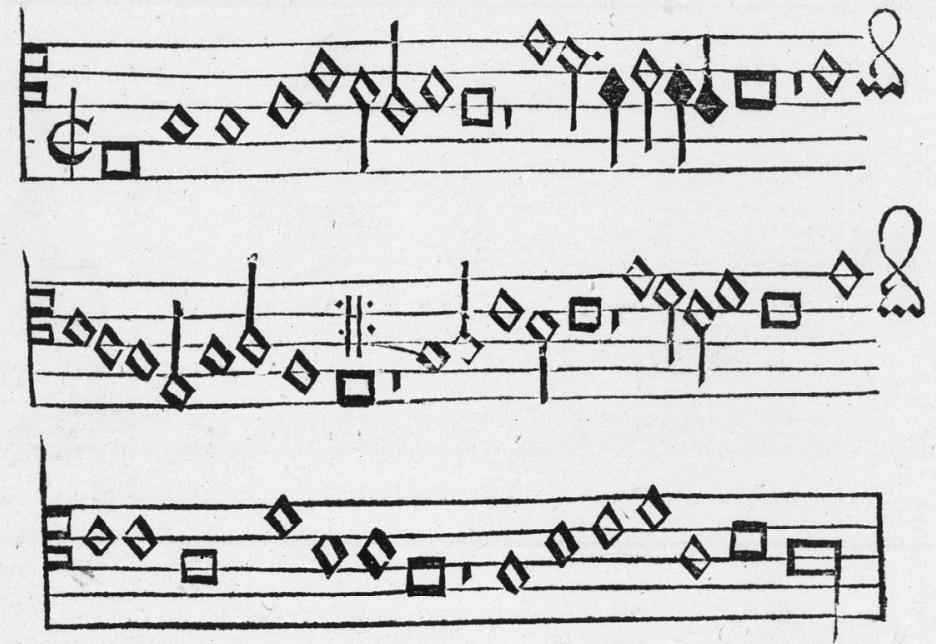

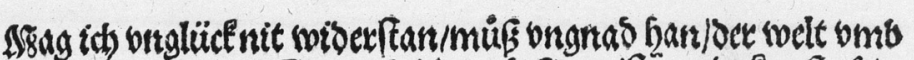

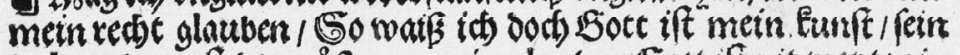

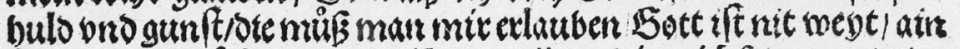

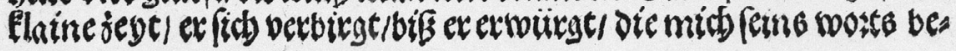
rauber.

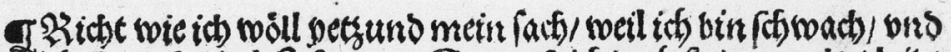
mith Eott foschtleft finden ) Go wais id ooch lain gwalt bletbt

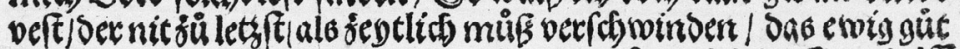

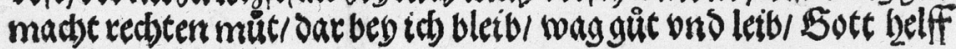
mix überwinder.

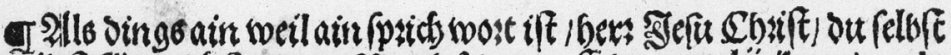

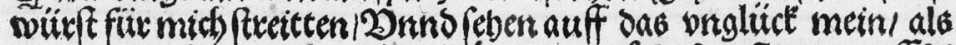

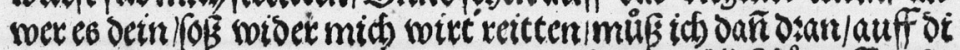

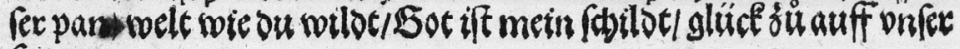
fetten.

Abbildung 2: Der Durchleuchtigsten Großmechtigen Fürstin ... New gaystlich Lied

[Augsburg: Heinrich Steiner] ca. I 529.

Kopie Deutsches Volksliedarchiv Freiburg: Bl fol. $173^{57}$

57 Für eine Reproduktion und die Erlaubnis der Veröffentlichung dieser Abbildung danke ich ganz herzlich Michael Fischer vom Deutschen Volksliedarchiv Freiburg. 
Das Magdeburger Gesangbuch geht auf das von Joachim Slüter in Rostock herausgegebene Gesangbuch von I 53 I zurück, in dem Mag ich Unglück allerdings ohne den Beisatz auftritt. ${ }^{58}$ Damit stellt sich erneut die oben bereits formulierte Frage: Wie kann es sein, dass der Name Marias von Ungarn, der bevorzugten Schwester des vom Papst persönlich eingesetzten Kaisers, in einem protestantischen Gesangbuch aufscheint?

In der Tat existieren zahlreiche Hinweise, die auf Verbindungen Marias zur reformatorischen Bewegung schließen lassen. ${ }^{59}$ Am bekanntesten ist die Tatsache, dass Martin Luther ihr nach der Schlacht von Mohács eine Publikation widmete: Vier trostliche Psalmen An die Königyn zu Hungern ausgelegt durch Martinum Luther. ${ }^{60}$ Den ersten in dieser Schrift aufgeführten Psalm, Erzürne dich nicht (Ps. 37), ließ Maria - und das ist bemerkenswert - in Luthers Übersetzung bereits vor dem ersten bekannten Druck der ihr gewidmeten Trostpsalmen und vor Mohács durch Thomas Stoltzer vertonen. ${ }^{6 I}$ Des Weiteren entspinnt sich die Debatte um Marias Glaubenshaltung an Geschehnissen auf dem Reichstag zu Augsburg I530. Über ihren Hofprediger Johannes Henckel ließ Maria einen Zettel mit fünf Fragen bezüglich der Einnahme des Abendmahls an Philipp Melanchthon richten, der sie zur Beantwortung an Martin Luther weiterleitete. Auch die ablehnende Antwort Luthers auf ein Praktizieren der Eucharistie sub utraque species „im Geheimen“ ist erhalten, sowie zahlreiche weitere Berichte lutherischer Parteigänger aus Augsburg über Marias Neigung zum Evangelium. ${ }^{62} \mathrm{Da}$ auch von der Gegenpartei Beschwerden über ihre Haltung vorliegen ist anzunehmen, dass die Gerüchte nicht jeglicher Grundlage entbehren. ${ }^{63} \mathrm{Im}$

58 Joachim Slüter's ältestes rostocker Gesangbuch vom Jahre 1531, hrsg. von C.M. WiechmannKadow, Schwerin I 858 [im Volltext unter Google Books ein Exemplar der Universiteitsbibliotheek Gent], fol. f iir .

59 Vgl. Georg Loesche, Die evangelischen Fürstinnen im Hause Habsburg. Eine historisch-psychologische Studie mit Benutzung archivalischer Quellen, Wien u.a. I904; Bart J. Spruyt, „,En bruit d'estre bonne luteriene': Mary of Hungary ( $505-58)$ and Religious Reform“, in The English Historical Review I09 (I994), S. 275-307; Katherine Walsh and Alfred A. Strnad, „Eine Erasmianerin im Hause Habsburg: Königin Maria von Ungarn (I505-58) und die Anfänge der Evangelischen Bewegung“, in Historisches Jahrbuch I I 8 (I998), S. 40-85; Rudolf Keller, „Maria von Ungarn und Martin Luther: Luthers Verbindung zur Königin“, in Fuchs/Réthelyi, Maria von Ungarn (wie Anm. I), S. 273-28 I. Auch publiziert in Rudolf Keller, Luthertum in der Vielfalt seiner Geschichte. Aufsätze zur Kirchengeschichte, Onlinepublikation Regensburg 2006, S. 5-IO. (online zugänglich unter http://www.uni-regensburg.de/Fakultaeten/phil_Fak_I/Evangelische_Theologie/pdfs/Luthertumkomplett.pdf)

60 Erstdruck: Wittenberg: Hans Barth i526 [VDi6 L 6968-L 6973] (online einsehbar: http://daten.digitale-sammlungen.de/bsbooo37II9/image_I)

6I Brief Thomas Stoltzers an Albrecht von Preußen vom 23. Februar I526, in Faksimile und Übertragung bei Hoffmann-Erbrecht, Thomas Stoltzer (wie Anm. 39), S. 33-36 und Tafel II.

62 Walsh, „Eine Erasmianerin“, S. 75-79.

63 Ebda. und Spruyt, ,,En bruit““ (wie Anm. 59). 
Jahr I 53I, als Maria bereits auf dem Weg war, ihre Statthalterschaft anzutreten, schrieb Lazarus Spengler an Veit Dietrich in Nürnberg in der Hoffnung, dass nun die „Niederland das Euangelion annehmen und an der Königin noch ein christenliche Regentin finden sollen “. ${ }^{64}$ Wenn Dietrich Luther dazu bringen könne, der Königin eine Ermahnung in diesem Sinn zu verfassen, so würde er damit ein nützliches und gutes Werk vollbringen. Aus einem weiteren Brief Spenglers an Dietrich ein knappes halbes Jahr später wird deutlich, dass Luther dieser Aufforderung nachgekommen ist. Aus dem Jahr I53 I hat sich auch tatsächlich eine Trostschrift Luthers erhalten, die an eine „Durchleuchtige, Hochgeborene Fürstin“ adressiert ist. ${ }^{65}$ Dem Inhalt nach zu urteilen könnte es sich dabei um das von Spengler angeregte Schriftstück an Maria von Ungarn handeln.

Maria zeigte sich also der Reformation gegenüber aufgeschlossen, und die Anhänger Luthers setzten zumindest in den Jahren um I 530 sehr große Hoffnungen in sie, obwohl sie nie öffentlich Partei ergriff, sondern ihre Person betreffend stets einen Ausgleich zwischen Familientreue und religiöser Überzeugung suchte. In der neueren Forschung geht man daher davon aus, dass Marias religiöse Tendenz weniger als lutherisch oder nicht zu deuten ist, sondern sie vielmehr eine Via-media-Position im Sinne eines „humanistischen Reformismus" des Erasmus von Rotterdam einnahm. ${ }^{66}$

\section{AUTORFRAGEN UND KIRCHENPOLITISCHES KALKÜL}

Eine Frage, die meist sehr prominent in der Auseinandersetzung mit dem geistlichen Mag ich Unglück nit widerstan auftritt, ist die nach dem Autor des Liedtextes. Verschiedentlich wurde sogar Martin Luther genannt, ${ }^{67}$ doch Spitta spricht sich eindeutig gegen diese Zuweisung aus. Einerseits mit Argumenten der Textüberlieferung, ${ }^{68}$ vor allem aber aus dem Grund, dass das Lied etwa in Slüters Gesangbuch von I53 I und dem Klug'schen von I 533 nicht wie andere mit Luthers Namen versehen ist, sondern sogar unter der Rubrik „nicht von den Unsern zu

64 Brief vom 22. April I 53 I, zitiert nach Keller, „Maria von Ungarn“ (wie Anm. 59), S. 279.

65 D. Martin Luthers Werke, Kritische Gesamtausgabe, Briefwechsel, 6. Bd.: I53 I-I533, Weimar I935, S. I94-I97, Nr. I 866 und Keller, „Maria von Ungarn“, S. 278-28 I.

66 Walsh, „Eine Erasmianerin“ (wie Anm. 59), S. 82-84 und Schwarz, „Leonhard Stöckel“ (wie Anm. I7), S. $324 \mathrm{f}$.

67 Wackernagel, Kirchenlied (wie Anm. 43) Bd. 3, S. I I9, Anmerkung zu Nr. I 56.

68 Dabei bezieht er sich auf Vorstudien von Karl Budde; Budde, „Kleinigkeiten“ (wie Anm. I8). Die Argumente werden in diesem Aufsatz an späterer Stelle noch einmal angeführt. 
Wittenberg, sondern anders woher durch fromme Männer gemacht" erscheint. ${ }^{69}$ Spitta selbst vertrat als Erster die heute weiterhin verbreitete These, dass Albrecht von Brandenburg den geistlichen Liedtext gedichtet hätte. ${ }^{70}$ Diese Annahme ist jedoch kaum haltbar, wie weitere der von Spitta vorgenommenen Zuweisungen an Albrecht. ${ }^{71}$ Noch als Hochmeister des Deutschen Ordens besuchte dieser seinen Bruder Georg in den Jahren I 522, I 524 und I 525 und traf dabei auch mit Maria zusammen..$^{72} \mathrm{Da}$ sie ähnlich gelagerte Interessen besaßen, entspann sich zwischen den beiden ein reger Briefwechsel..$^{73}$ Aus diesem Grund hätte der als Lieddichter verbürgte Albrecht durchaus ein tröstliches Lied für Maria nach dem Vorbild der weltlichen Fassung dichten können. Es erschiene in diesem Fall aber merkwürdig, dass Albrechts Liedtext nicht zur Hand war, als für seine Frau Dorothea um I 540 bis I 547 eine Liedersammlung zusammengestellt wurde. ${ }^{74}$ Man nimmt zwar an, dass die Stimmbücher von Melchior Kugelmann am dänischen Hof in Kopenhagen geschrieben wurden, doch gerade für deren Erstellung ist ein Austausch von Musikalien mit dem Preußischen Hof vorauszusetzen oder doch zumindest anzunehmen. In der heute in Brüssel aufbewahrten Handschrift B-Br II.3843 ist Ludwig Senfls Satz Mag ich Unglück mit einer hinzukomponierten 5. Stimme und der weltlichen Fassung des Textes aufgezeichnet. Da Textform und Melodie beider Fassungen jedoch ident sind, hätte man ohne Probleme auch den geistlichen Text unterlegen können, der

69 Spitta, „Die ungarischen Königslieder“ (wie Anm. 23), S. 332-339. Vgl. auch WiechmannKadow, Joachim Slüter's ältestes rostocker Gesangbuch (wie Anm. 58) und Das Klug'sche Gesangbuch 1533, hrsg. von Konrad Ameln, Kassel und Basel I983, fol. I $3 \mathrm{I}^{\mathrm{r}}-\mathrm{I} 32^{\mathrm{r}}$.

70 Spitta, „Die ungarischen Königslieder, S. 325-242. Spittas These wird beispielsweise auch in DKL III/I.I Ec27 wieder aufgegriffen, dort allerdings ausschließlich bei dem Eintrag von Johann Walters Satz Mag ich Unglück nit widerstan.

7I Siehe Peter Gerrit Thielen, Die Kunst am Hofe Herzog Albrechts von Preußen (1525-1568), Göttingen I953 (Göttinger Bausteine zur Geschichtswissenschaft I2), S. 92-IO5.

72 So war Albrecht etwa bei den Krönungsfeierlichkeiten von Ludwig (9. Mai I 522) und Maria (I. Juni) in Prag zugegen.

73 Siehe Zoltán Csepregi, „,... ich will kain fleis nit sparen“ - Königin Maria von Ungarn und das Haus Brandenburg“", in Fuchs/Réthelyi, Maria von Ungarn (wie Anm. I), S. 59-72.

$74 \mathrm{Zu}$ dieser Handschrift siehe auch den Beitrag von Stefan Gasch in diesem Band. Die Datierung folgt der von Henrik Glahn vorgeschlagenen (Henrik Glahn „En ny kilde til belysning af det preussiske hofkapels repertoire på Hertug Albrechts tid“, in Svensk Tidskrift för Musikforskning 43 [I96I], S. I45-I6I), die auch in Census-Catalogue of Manuscript Sources of Polyphonic Music 1400-1550, compiled by the University of Illinois Musicological Archives for Renaissance Manuscript Studies, 5 Bde., Neuhausen-Stuttgart I979-I988 (Renaissance Manuscript Studies), Bd. I, S. 96 und Bd. 4, S. 296 übernommen wurde. Es könnte natürlich sein, dass Albrecht den selbstgedichteten Text verlegt hatte, was ihm - Jahre später - offensichtlich auch mit vier seiner Psalmbearbeitungen passierte. Er berichtet in einem Brief an Hans Funck vom 3.9.I557: „... ich schicke euch hie meine 4. Psalmen/ die ich verlohren zum theil gehabt/ hab sie wiederumb zusammen bracht/ ..." Zitiert nach Thielen, Die Kunst, S. 96. 
zudem besser in den Kontext der Brüsseler Stimmbücher gepasst hätte. Der dort $\mathrm{zu}$ findende Lied- und Notentext ist jedoch eindeutig aus der ersten Auflage von Forsters erstem Liederdruck Ein außzug guter alter und newer Teutscher liedlein kopiert worden. ${ }^{75}$ Aus diesem eben auf dem Markt erschienen Druck wurde auch noch ein weiteres von Senfl vertontes Lied mit dem Akrostichon "MA-RI-A" übernommen: Maß Zucht Verstand. ${ }^{76}$

Sehr häufig begegnet der geistliche Liedtext auch in Liedflugschriften, da diese jedoch nur selten (im Falle der Mag ich Unglück überliefernden niemals) mit einem Druckdatum versehen sind, können sie nur bedingt zur Datierung und zur Rekonstruktion der Genese der unterschiedlichen Liedtexte beitragen. Hält man sich nun allein an die mit Jahreszahl versehenen Quellen, so scheint die Verbreitung der geistlichen Fassung von Mag ich Unglück erst ab I 529, mit der verschollenen Erstauflage des Klug'schen Gesangbuchs, einzusetzen. ${ }^{77}$ Mit diesem Datum fällt ein bemerkenswertes Dokument zusammen, auf das bereits Theodor Kolde I 895 im Zusammenhang mit dem Lied der Königin von Ungarn hinwies. ${ }^{78}$ Es handelt sich um einen Brief von Georg von Brandenburg an seine Statthalter und Räte, dem er ein - nach eigener Aussage - von der Königin von Ungarn gedichtetes Lied beilegt. Zwar ist das Lied selbst heute nicht mehr in

75 RISM I $539^{27}$, Nr. I02. Die 7. und 8. Zeile der 3. Strophe sind in den bekannten Textzeugen der weltlichen Liedfassung sehr unterschiedlich gestaltet. Bei Forster wie auch in B-Br II.3843 lauten sie: „D[a]rumb will ich/ auch [allzeit] mich“. In der ersten Auflage wurde bei Forster das Wort „allzeit“ ausgelassen (ab der 2. Auflage I 543 verbessert) und auch in B-Br II. 3843 ist das Wort nicht vorhanden, zudem lesen beide zu Zeilenbeginn „Drumb“. Ein weiterer Hinweis auf Forster als Vorlage ist, dass diese beiden Quellen als einzige die Schlusszeile als „Glück zu auf meiner Seiten“ wiedergeben, während es in allen anderen „u nser Seiten“ lautet.

Auch der Notentext der beiden Quellen ist ident, und in keiner von ihnen werden Ligaturen verwendet, was im Falle des Drucks wohl auf die technischen Schwierigkeiten zurückzuführen ist. Die in CH-Bu F X I7-20 aufgezeichnete Niederschrift setzt dagegen häufig Ligaturen ein (v.a. im Bass) und fasst kleine Notenwerten zu größeren Einheiten zusammen (z.B. Beginn der Altstimme). Zudem wurde dort in keiner Stimme das Wiederholungszeichen eingezeichnet und der Alt verbleibt im Schlussklang auf der Quint und wechselt nicht in die Terz.

76 Da beide Lieder in B-Br II. 3843 hintereinander als Nr. 6 und 7 aufgezeichnet sind, nimmt Glahn an, dass auch Maß Zucht Verstand an Maria von Ungarn gerichtet ist: Henrik Glahn „En ny kilde“ (wie Anm. 74), S. I48. Der einzige Hinweis darauf, dass diese Vermutung zutreffend sein könnte, ist dem Liedinhalt zu entnehmen. Dort wird - entgegen den Gattungskonventionen - nicht die Schönheit der Angesprochenen besungen, wohl aber ihr Verstand. Dies korrespondiert mit den zeitgenössischen Beschreibungen Marias, die meist Intelligenz aber mangelnde Schönheit konstatieren; vgl. Anm. 52 in diesem Aufsatz.

77 Erhalten ist eine spätere Auflage: Geistliche lieder auffs new gebessert zu Wittemberg. D. Mart. Luth. XXXiij., Wittenberg: [Johann Klug] I 533 [DKL I $\left.533^{\circ 2}\right]$.

78 Theodor Kolde, „Markgraf Georg von Brandenburg und das Glaubenslied der Königin Maria von Ungarn“, in Beiträge zur bayerischen Kirchengeschichte, II. Band (I 896), S. 82-89. 
Verbindung mit dem Brief überliefert (in dem auch weder Titel noch Incipit genannt werden), die Wahrscheinlichkeit, dass es sich dabei um die geistliche Variante von Mag ich Unglück nit widerstan handelte, ist jedoch sehr groß: Zum einen ist hier die Brücke zu Maria von Ungarn gegeben, zum anderen passt die inhaltliche Aussage zu der intendierten Funktion als reformatorisches Trostlied. Friedrich Spitta, dem Koldes Aufsatz bekannt war, geht auf dieses Dokument zwar ein, ist aber überzeugt, dass Georg sich in der Autorangabe geirrt haben müsse. ${ }^{79}$ Für ihn liegt die Bedeutung des Briefs allein darin sicherzustellen, dass Georg von Brandenburg keinesfalls selbst das Lied verfasste und vielmehr dessen Bruder Albrecht als Dichter in Frage käme. Auf Spittas vernichtendes Urteil hin, fand der Brief erst in letzter Zeit wieder vermehrt Beachtung. ${ }^{80}$ Es seien im folgenden Absatz einige Meinungen in der Auseinandersetzung der letzten Jahre wiedergegeben.

Zoltán Cspregi folgt Spittas Argumenten dahingehend, dass Albrecht von Preußen der Urheber des weltlichen Maria-Liedes gewesen sein könnte, das aber nach seiner Meinung erst I 525 entstand (offensichtlich ist ihm die Tatsache, dass Senfls Vertonung bereits I 523 existierte unbekannt). In Bezug auf die Aussage und Glaubwürdigkeit von Georgs Brief widerlegt er alle Argumente, die von Spitta gegen Marias Autorschaft der geistlichen Kontrafaktur gesammelt wurden. ${ }^{81}$ Der deutschen Sprache war sie mächtig ${ }^{82}$ und die kirchenpolitischen Ereignisse im Umkreis Marias lassen sich durchaus mit Georgs Aussagen in Einklang bringen, der zu dieser Zeit immer noch als ein Intimus der Königin zu sehen ist. ${ }^{83}$ Katherine Walsh hält ebenso Koldes Briefbeleg für so überzeugend, dass sie für beide Textfassungen ohne weitere Argumente erneut Maria von Ungarn als Autorin in den Kreis der möglichen Verfasser aufnimmt. ${ }^{84}$ Auch in zahlreichen auf schöpferisch tätige Frauen konzentrierten Publikationen der

Friedrich Spitta, „Die ungarischen Königslieder: Ein Blatt aus der hymnologischen Geschichte der Reformationszeit“, in Monatsschrift für Gottesdienst und kirchliche Kunst I4 (I909), S. 325-242, zu Koldes Aufsatz S. 330.

80 Walsh, „Eine Erasmianerin“ (wie Anm. 59), S. 75; Zoltán Csepregi, „Court Priests in the Entourage of Queen Mary of Hungary“, in Mary of Hungary. The Queen and Her Court 15211531, hrsg. von Orsolya Réthelyi u.a., Budapest 2005, S. 46-6I [online verfügbar unter: http://www.mtakpa.hu/kpa/download/I I23004.pdf]; Karl W. Schwarz, „Leonhard Stöckel“ (wie Anm. 17), S. 324; Orsolya Réthelyi, Mary of Hungary in Court Context (1521-1531), Diss. Central European University, Budapest 2010 [online einsehbar unter http://www.etd.ceu.hu/20Io/rethelyio.pdf], S. I 87-I 89.

8 I Spitta, „Königslieder“, S. 333-335.

82 Siehe den häufig zitierten humorvollen Brief Marias an Albrecht aus dem Jahr I 523, der im originalen Wortlaut auch bei Rethélyi, Mary of Hungary, S. I 87, Anm. 794 abgedruckt ist.

83 Csepregi, „Court Priests“, S. 58.

84 Walsh, „Eine Erasmianerin“ (wie Anm. 59), S. 75. 
letzten Jahren wird die Annahme, dass Maria den Liedtext selbst gedichtet hätte, (meist mit wenig Bedenken) aufgenommen. ${ }^{85}$

Sicherlich vermag der von Kolde vorgebrachte Brief nicht die Frage nach dem Autor der geistlichen Liedfassung letztgültig zu klären, die genauen Umstände seiner Entstehung bleiben weiter im Dunkeln, doch könnte hierin ein Schlüssel für die weitere Verbreitung und Popularität des Liedes zu finden sein, der bisher über das Rätsel der Autorschaft nicht beachtet wurde. Der Brief Georgs richtet sich an die Statthalter und Räte Ansbachs, um sie mit Verweis auf die Verhältnisse in Schlesien und der Oberlausitz in ihrer evangelischen Ausrichtung zu bestärken. Dort richte man sich in kirchlichen Angelegenheiten nach den reformatorischen Vorstellungen - und widersetze sich damit einem jüngst von Ferdinand ausgegangenen Mandat -, während man andererseits dem König „in zeitlichen sachen, mit leyb und gut gehorsam“ sei. Die Passage gegen Ende des Briefes, in der Georg auf das Lied hinweist, lautet im Original:

Wir schicken euch auch hier Jnnen verschlossen, Ein lied das des konigs Swester konigin Maria, wider Jren bruder gemacht, do er Jr einen Cristlichen prediger verJagt hat, vnd dieweÿl Jm land zu Merhern, das Euangelion lauter gepredigt, wurdet sich, di konigin ytzt doselbsthien, vf etliche Jre eigene guter thun, Also das got vnnd sein wort Jn ewigkeit bleÿbt vnnd stercker ist, dan alle porten der hellen, ${ }^{\star}$ solch liedt wollet herr Hannsen Rurern vonn vnnsern wegen geben, das er vnns di andern zwo stÿm darczu seczen lasse, vnnd Jr alle durch dises alles auch gesterckt vnnd getrost sein. bey gottes wort zu bleyben, Auch dasselbig vber alle ding zu lieben vnnd zufudern.$^{86}$

* der auch sein macht an disem schwachen weybsbild sehen lest, vnd dadurch, vil starcker ... nn [nicht lesbar] kleynmutigkeit offenbart

Markgraf Georg hatte nach dem Tod seines Bruders Casimir I527 stellvertretend für dessen minderjährigen Sohn Albrecht Alcibiades die Herrschaft in Brandenburg-Kulmbach übernommen. Er war wie sein Bruder Albrecht von Preußen eindeutig der Reformation zugewandt und trachtete danach, diese auch in seinen Ländereien voranzutreiben. Folgt man den Aufenthaltsorten Georgs im

85 Albrecht Classen, Deutsche Frauenlieder des fünfzehnten und sechzehnten Jahrhunderts, Amsterdam/Atlanta 1999 (Amsterdamer Publikationen zur Sprache und Literatur I36), S. I7If.; ders., „Mein Seel fang an zu singen“ (wie Anm. 56), S. 27of.; Linda Maria Koldau, Frauen Musik - Kultur. Ein Handbuch zum deutschen Sprachgebiet der Frühen Neuzeit, Köln u.a. 2005, S. 53 .

86 Staatsarchiv Nürnberg, Bestand Fürstentum Ansbach, Religionsakten (Rep. I I I), Bd. I I, fol. $324^{\mathrm{r}}-326^{\mathrm{v}}$, hier fol. $324^{\mathrm{v}}$ und $326^{\mathrm{r}}$. Der gesamte Brief findet sich auch abgedruckt bei Kolde, „Markgraf Georg“ (wie Anm. 78), S. 84-86. 
Zeitraum der Entstehung des Briefs, also Ende I528 und Anfang I529, ${ }^{87}$ stellt man fest, dass dieser, in Bemühung um die religiöse und finanzielle Lage des Markgrafentums, gerade in den fraglichen Monaten erstaunliche Entfernungen zurücklegte. Am 27. Dezember I 528 ist Georg noch in Ansbach nachgewiesen, dann berichtet ein Brief Martin Luthers an Kurfürst Johann von Sachsen vom 9. Januar $1529,{ }^{88}$ dass Georg die kursächsischen Länder durchquere, und tatsächlich zog er bereits am 4. Januar durch Wittenberg. ${ }^{89}$ Der Liedbrief vom I 5 . Januar ist in Frankfurt an der Oder geschrieben, von wo aus sich Georg über Oppeln (heute Opole/Polen) auf seine Besitztümer nach Jägerndorf (heute Krnov/Tschechien) begab, wo sein Aufenthalt am 3. Februar belegt ist. In einer Zeitspanne von etwas über einem Monat legte Georg damit eine Strecke von ca. Iooo Kilometern zurück. Auch in Jägerndorf verweilte er nicht lange, am 7. März finden wir ihn bereits auf dem Rückweg in Liegnitz (heute Legnica/Polen) und am 27. März wiederum in Ansbach, von wo aus er aber sofort zum Reichstag nach Speyer weiterreiste und am 8. April I 529 eintraf.

Die Frage, wo und wann Georg die geistliche Kontrafaktur von Mag ich Unglück kennengelernt haben könnte oder ob er sie gar in Auftrag gab, ist ohne weitere Quellenfunde nicht zu lösen. Es wäre aber zu vermuten, dass er in Ansbach, das er erst wenige Wochen zuvor verlassen hatte, noch nicht im Besitz des Liedes war. Unterwegs könnte er es kennengelernt und im Januar I 529 in die Heimat geschickt haben, als Stärkung in der reformatorischen Überzeugung gegen eine starke altgläubige Partei. ${ }^{90}$ Er veranlasste auch seinen Stiftskaplan Hans Rurer, „das er vnns di andern zwo stÿm darczu seczen lasse “. Ein zu der Zeit in Ansbach ansässiger Komponist, bei dem man eine solche Komposition in Auftrag hätte geben können, ist mir nicht bekannt. ${ }^{91}$

Georg könnte auch der Übermittler des Liedes nach Wittenberg gewesen sein, wo es in das gerade im Entstehen begriffene lutherische Gesangbuch - und dort folgerichtig unter den Gesängen der „,anderen“, nicht in Wittenberg ansässigen - Aufnahme fand. Auf jeden Fall kann man Georgs Übersendung des Lie-

87 Louis Neustadt, „Aufenthaltsorte des Markgrafen Georg von Brandenburg“, in Archiv für Geschichte und Alterthumskunde von Oberfranken I 5/Heft 3 (I 883), S. 23 I-257 und Karl Schornbaum, Zur Politik des Markgrafen Georg von Brandenburg, München 1906.

88 D. Martin Luthers Werke, Kritische Gesamtausgabe, Briefwechsel, 5. Bd.: I529-I530, Weimar I934, Nr. I37I.

89 Schornbaum, Georg von Brandenburg, S. 344, Fn. 266.

90 Vgl. ebda. S. 56-63.

9I Es sind einige anonym überlieferte Sätze zu Mag ich Unglück erhalten, denen, soweit mir die Quellen einsehbar waren und ein Text überliefert ist, stets der geistliche Text zugrunde liegt. Der anonyme 4-stimmige Satz in D-Usch 236 a-d und derjenige von Caspar Bohemus (RISM I $539^{27}$, Nr. 5I) überliefern die „nicht-lutherische“ Textfassung (s.u.), bei Caspar Bohemus wird allerdings ein nur marginal an den Senfl'schen angelehnter c.f. verwendet. 
des neben seinen Sorgen um die glaubenspolitische Lage in den eigenen Ländern eine weitere taktische Funktion zuschreiben: Der erwählte Kaiser Karl hatte zu einem Reichstag in Speyer aufgerufen, der schließlich am I5. März eröffnet wurde. Auf diesem Reichstag sollte neben der Bedrohung durch die Türken auch das Problem der Uneinigkeit des Glaubens angesprochen und nach Karls Vorstellungen - die Ferdinand in Speyer vertrat - mit Mehrheitsbeschluss die reformatorische Bewegung aufgehalten werden. In dieser Entschlossenheit war die Absicht der kaiserlichen Seite den der Reformation wohlgesinnten Landesherren und den Städten wohl nicht bekannt, dennoch war die Stimmung sicherlich nicht zu verkennen. Die Verbreitung eines Liedes mit reformatorischem Inhalt, von dem behauptet wird, die Schwester des Kaisers habe es im Trotz gegen ihre Brüder gedichtet, könnte in dieser Situation Hoffnung und Mut unter den Anhängern Luthers stärken. Damit schien man eine mächtige Fürsprecherin aus dem Hause Habsburg an der Seite zu haben, die ihre Brüder durchaus beeinflussen konnte. Der Übermittler Georg von Brandenburg bürgte sicherlich auch zur damaligen Zeit für die Glaubhaftigkeit der Autorschaft Marias, da er doch lange Zeit mit ihr in engem Kontakt gestanden hatte. Für die sofortige Popularität des Liedes könnten die zwei Bedeutungsebenen von Kontrafaktur und Vorlage gesorgt haben: Mit der Melodie wurden Klage und Hoffnung bezogen auf Maria und die ihr widerfahrene Katastrophe der Schlacht von Mohács - transportiert, mit dem neuen Text wurden darüber hinaus die lutherischen Hoffnungen genährt.

Dass Georg das Lied in Wittenberg kennenlernte, erscheint dagegen unwahrscheinlich, da Wittenberg tatsächlich nicht die einzige Quelle für die rasche Verbreitung der geistlichen Fassung von Mag ich Unglück nit widerstan gewesen sein kann. In der Überlieferung scheiden sich deutlich zwei Textvarianten, von denen eine „lutherische“ vor allem in den Gesangbüchern auftritt, während die andere heute vor allem in Flugpublizistik erhalten ist. Die textlichen Unterschiede arbeitete bereits Karl Budde mit Blick auf die Autorfrage heraus. ${ }^{92}$ Kleine Abweichungen sind in jeder Strophe zu finden, hier sollen nur die markantesten aufgeführt werden: 
EINBLATTDRUCK CA. I 529

I. Strophe, Zeile 4-6

So waiß ich doch Gott ist mein kunst, sein huld vnd gunst,

die muß man mir erlauben, ...

3. Strophe, Zeile 2-3

herr Jesu Christ,

du selbst würst für mich streitten, ...

3. Strophe, letzte Zeile

... glück zu auff vnser seitten.
GESANGBUCH KLUG I 533

So weis ich doch es ist mein kunst, Gotts huld vnd gunst,

die mus man mir erleuben, ...

Herr Jhesu Christ,

du wirst mir sthen zur seitten, ...

... der wird mich wol beleiten.

Diese beiden Textvarianten sind in sich stabil, und wie bereits Budde und Spitta bemerkten, mutet die in den Gesangbüchern überlieferte weniger kämpferisch an, und man muss wohl von einer Bearbeitung für den Druck ausgehen. Abgeleitet von der „nicht-lutherisch-redigierten“ Fassung existiert auch noch eine textliche Erweiterung um drei Zeilen; das Lied wurde dann freilich nicht mehr auf dieselbe Melodie, sondern im Ton Ungnad begehr ich nit von ihr gesungen. ${ }^{93}$

In den Flugschriften und Einblattdrucken ist das Lied wie bereits erwähnt immer als das der Königin von Ungarn ausgewiesen, während in Gesangbüchern darauf seltener und erstmals I 534 hingewiesen wird. Gerade in den in Wittenberg gedruckten und unter Luthers Aufsicht entstandenen Gesangbüchern findet sich allerdings kein Hinweis auf diese Beziehung. Wollte Luther nach der Widmung der Trostpsalmen, die Maria in einige Bedrängnis gegenüber ihrem Bruder gebracht hatte, vorsichtiger vorgehen? Auch der Austausch der fünf Fragen auf dem Reichstag in Augsburg I 530 wurde, wie es scheint, in großer Heimlichkeit und mit verschiedenen Sicherheitsvorkehrungen (wie der verschlüsselten Umschreibung von Namen) vorgenommen. ${ }^{94}$ Oder war man sich der Gesinnung Marias doch nicht ganz sicher, so dass man einen solchen Hinweis lieber nicht schwarz auf weiß in dem als Vorbild zur weiteren Verbreitung konzipierten Gesangbuch anbringen wollte? 


\section{WEITERLEBEN IN DER KONTRAFAKTUR}

Die Hoffnungen, die man in Maria von Ungarn als Unterstützerin der Reformation setzte, scheinen tatsächlich groß gewesen zu sein. Das lässt sich beispielsweise an der Korrespondenz im protestantischen Lager im Umkreis des Augsburger Reichstags I 530 ablesen, auf dem Maria auch anwesend war..$^{95}$ Davon, dass diese Hoffnungen noch lange Zeit aufrecht erhalten wurden, zeugen etwa die Notendrucke, die Sigmund Salminger ihr noch in den Jahren I 548/49 und vielleicht auch schon I 540 widmete. ${ }^{96}$ Hierin mag auch der Schlüssel für das scheinbar ungebrochene Interesse an den mit Maria in Verbindung gebrachten Liedern zu suchen sein. Ein Blick auf das Erscheinungsdatum der Flugschriften zeigt, dass eine Reihe von Drucken mit Mag ich Unglück nit widerstan um I 530 entstanden sind, aber auch in der Zeit um I 540/45 nicht aus dem Programm genommen wurden. Zahlreiche geistliche Kontrafakturen, etwa das schon früh bezeugte Wider die drei Ertzfeind der Seelen betitelte Lied O Gott verleih mir dein Genad, ${ }^{97}$ das in Flugschriften und auch lutherischen Gesangbüchern häufig im Verbund mit dem Geistlichen Buchsbaum von Hans Witzstat auftritt, scheinen allein aus dem Grund den Ton Mag ich Unglück heranzuziehen, da er in den Gesangbüchern präsent und musikalisch ansprechend war. ${ }^{98}$ Bemerkenswert ist ein Traditionsstrang, der das Lied mit dem Sterben, Begräbnis oder Tod in Verbindung bringt. Ihm sind die Kontrafaktur Mag ich dem Tod nit widerstan ${ }^{99}$ und das Klaglied vm [m]

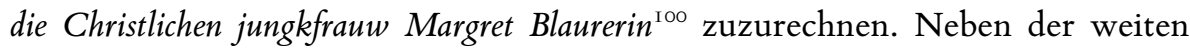
Verbreitung dürften hier inhaltliche Bezugspunkte zum kontrafazierten Lied für

95 Vgl. etwa Spruyt, „,En bruit““ (wie Anm. 59), S. $287 \mathrm{ff}$.

96 Es handelt sich dabei um die Einblattdrucke des Sancta Maria succurre von Benedict Appenzeller [RISM AA I29Ia; auch auf ein Leintuch gedruckt: B-Br VI I8.6I 3 E] und Pro gratiarum actione mit 3 Kanons von Rogier Pathie, sowie den Sammeldruck Cantiones selectissimae. Liber secundus [RISM I $549^{\text {II }}$ ]. Für weitere Informationen und eine weitere vermutete Widmung (Selectissimae cantiones [RISM I 5407]) siehe Birgit Lodes, „Sigmund Salmingers Selectissimae cantiones (Augsburg I 540) als musikalischer Geschenkdruck für Königin Maria von Ungarn“, in Gutenberg Jahrbuch 83 (2008), S. 93-106.

97 VDi6 S I6I8-I624.

98 Siehe auch die in DKL I.I B33A angegebenen Kontrafakturen, darüber hinaus existieren noch weitere; vgl. Kurt Hennig, Die geistliche Kontrafaktur im Jahrhundert der Reformation. Ein Beitrag zur Geschichte des deutschen Volks- und Kirchenliedes im XVI. Jahrhundert, Halle I909, S. I 84 f. und passim.

99 Auch Ein Sendbrieff sampt einem geistlichen Lied, in disen sterblichen zytten lieblich vnd nutzlich zu lesen vnd singen, [Bern um I 550] [VDI6 ZV 27692].

Ioo Ambrosius Blaurer, [Zürich: Christoph Froschauer d.Ä.] I 542 [VDı6 B 5690]. Mag ich Unglück (in der geistlich „lutherischen“"Fassung) erscheint beispielsweise auch im Kontext einer Leichenpredigt, die I655 in Hannover gedruckt wurde [VDI7 I :037977V]. 
die Wahl ausschlaggebend gewesen sein: Das Anrufen Gottes in einer Not- bzw. Trauersituation und die Präsenz des Todes (mit Ludwigs Tod in der Schlacht). ${ }^{\text {Ior }}$

Weitaus interessanter in Bezug auf die Liedvorlage und die Verbindung mit Maria von Ungarn sind jene Kontrafakturen, die auf aktuelle Ereignisse bezogen sind und in der Zeit des Schmalkaldischen Krieges und des Reichstags in Augsburg I 547/48 entstanden. ${ }^{102}$ Maria wusste sich nach dem Verlust ihres Hofes in Buda nach einer Zeit der Unsicherheit gut zu positionieren. Ihre Intelligenz, strategische Begabung und ihre Ungebundenheit als kinderlose Witwe machten sie nach dem Reichstag von Augsburg I $530 \mathrm{zu}$ einer wichtigen Korrespondentin und Vertrauten sowohl Karls V. als auch Ferdinands I., so dass ihr zumindest für diese Zeit sicherlich die Rolle einer „First Lady“ im Reich zugesprochen werden kann. Auch wenn sie sich in der Öffentlichkeit häufig bewusst in den Schatten ihrer Brüder stellte und ihre Briefe mit Unterwürfigkeitsfloskeln gespickt sind, wusste sie sehr wohl ihre Interessen in die Reichspolitik einzubringen. ${ }^{103}$ Daher erscheint es bezeichnend, wenn ein Huldigungslied auf Kaiser Karl V. im Ton von Mag ich Unglück nit widerstan entsteht. ${ }^{104}$ In der ersten Strophe scheint sich die Kontrafaktur auch in der Wortwahl dem Vorbild anzuschließen. „Kein Gwalt bleibt fest" (Mag ich Unglück in der geistlichen, nicht-lutherischen Fassung: 2. Strophe, 4. Zeile) und „Herr Jesu Christ, du selbst wirst für mich streiten“ (ebda. 3. Strophe, 2./3. Zeile) finden in „Kein Gwalt auf dieser Erd bleibt fest“ und „wird Gott selbst für mich streiten“ (siehe folgende Seite) ihre Entsprechung. Damit scheint auch die Frage gelöst, welche Textfassung als Vorlage diente, denn nur mit der geistlichen, „nicht-lutherischen“ Textvariante, die am häufigsten als Lied der Königin von Ungarn ausgewiesen ist, stimmen diese Partien überein. Vielleicht wollte man dem „Führungsteam“ - Karl und seiner Schwester - einfach eine Freude bereiten, indem man das Maria-Lied wieder

IOI Siehe auch Gabriele Haug-Moritz, „,Zu Lob und Ehre Römischer Kaiserlicher Majestät“. Karl V. in der pro-kaiserlichen Liedpublizistik des Schmalkaldischen Krieges (I 546/47)“, in Plus ultra. Die Welt der Neuzeit. Festschrift für Alfred Kohler zum 65. Geburtstag, hrsg. von Friedrich Edelmayer, Martina Fuchs, Georg Heilingsetzer und Peter Rauscher, Münster 2008, S. IO3-I 22, hier S. I I2f.

IO2 Auf der Tagung Kultur-und kommunikationshistorischer Wandel des populären Liedes im 16. Jahrhundert am 27. und 28. November 2010 in Freiburg hielt Gabriele Haug-Moritz einen Vortrag zu diesem Thema mit dem Titel „Lieder in der Flugschriftenpublizistik des Schmalkaldischen Krieges (I 546/47)“; die Beiträge werden unter dem Tagungstitel, hrsg. von Michael Fischer und Nils Grosch, publiziert.

I03 Laetitia Gorter-van Royen, „Maria von Ungarn als Korrespondentin“, in Fuchs/Réthelyi, Maria von Ungarn (wie Anm. I), S. 47-58.

I04 Zur Wahl des Mediums Lied in der pro-kaiserlichen Publizistik der Zeit siehe: Haug-Moritz, „,Zu Lob und Ehre““ (wie Anm. Ior), hier S. Io8-I Io. 
aufgriff. Gleichwohl verbergen sich sicherlich noch weitere Absichten hinter der Wahl der Vorlage.

Kain gwalt vff diser erd bleibt fest

Der sich nit lest

Von Gott regiern vnd leiten.

Dann Gott in alweg ist der Herr,

Dem breyß vnd eer

Geburt zu allen zeiten.

Dem ich mich ergeb

Die weil ich leb.

In seynen schutz:

Dem feind zu trutz

Wirt Got selbs für mich streyte[n].

(Ain New lied zu eeren Kö. Kayserlich. Mayestat, Caroli des fünffen,

I. Strophe des deutschen Liedtexts, nach VDi6 N I3 I5)

Kein Gwalt auf dieser Erd bleibt fest ist eine I I-strophige Kontrafaktur auf Mag ich Unglück, deren Strophenanfänge das Akrostichon: CAROLVS Der fünfte Römischer Kaiser $\mathrm{Zu}$ allen zeytten Merer des Reychs, bilden. ${ }^{\text {I05 }}$ Es tritt in der Flugpublizistik erstmals im Jahr I 546 auf, in Verbindung mit einem Brief Martin Luthers: ${ }^{\text {:06 }}$

Ein New Lied von der Weltlichen Oberkait. Jtem Ein Rathschlag Doctoris Martini Lutheri/ Ob dem Kaiser/ so er jemands mit gewalt/ des Euangelij halben/ vberziehen wolte/ mit rechte widerstandt geschehen möge/ Etwan an Churfürsten Johansen seliger (vngfehrlich jm I53I. Jar) geschrieben.

Diese auf den ersten Blick merkwürdig anmutende Kombination entspringt einer Taktik der kaiserlichen Publizistik, die auch bei der Wahl des Tones Mag ich Unglück für das Preislied auf Karl V. eine Rolle gespielt haben kann: den Gegner mit seinen eigenen Waffen zu schlagen. Luther stand einem bewaffneten Widerstand gegenüber dem Kaiser - der höchsten Obrigkeit im Reich - zu-

IO5 Liliencron, Die historischen Volkslieder (wie Anm. I I), Bd. 4, Nr. 532.

io6 VDi6 ZV i 62 I. Beschreibung des Berliner Exemplars in Eberhard Nehlsen und Gerd J. Bötte, Berliner Liedflugschriften. Katalog der bis 1650 erschienenen Drucke der Staatsbibliothek zu Berlin - Preußischer Kulturbesitz, 3 Bde., Baden-Baden 2008/2009 (Bibliotheca Bibliographica Aureliana 2 I 5-2 I 7), Bd. 2, Nr. I696.

Eine weitgehend identische Flugschrift mit einem weiteren Loblied auf Herzog Moritz von Sachsen: VDi6 N I288, online einsehbar unter: http://daten.digitale-sammlungen.de/ bsbooo3 I 359 /image_I. 
nächst sehr skeptisch gegenüber. Er argumentierte mit einem Zitat aus der Bibel: „JEderman sey vnterthan der Oberkeit / die gewalt vber jn hat. Denn es ist keine Oberkeit / on von Gott / Wo aber Oberkeit ist / die ist von Gott verordnet. Wer sich nu wider die Oberkeit setzet / Der widerstrebet Gottes ordnung ..." (Römer, I 3 , If.). ${ }^{107}$ Luther revidierte diese Ansicht später dahingehend, dass sich der Papst des Kaisers als Werkzeug bediene und Kaiser und Kurfürsten das Reich gemeinsam regierten, und Notwehr somit erlaubt sei. Die kaiserliche Partei ließ dennoch zu Propagandazwecken Luthers älteren Brief, strategisch mit dem Preislied Karls kombiniert, verbreiten. ${ }^{108}$ Auch der Griff nach protestantischem Liedgut für Karl verherrlichende Kontrafakturtexte ist von ähnlichen Hintergedanken begleitet. Neben Mag ich Unglück findet sich sogar ein Text auf das Luther-Lied Aus tiefer Not. ${ }^{\text {I09 }}$ Sich der bekannten Melodien bedienend, hoffte man auf eine große Verbreitung gerade in den protestantisch beeinflussten Gebieten. ${ }^{\text {IIO }}$

Das Karlslied im Ton Mag ich Unglïck wurde aber auch separat als Einblattdruck mit einem entsprechenden Bildprogramm gestreut. ${ }^{I I I}$ Daneben entstand eine Cantilena imperatoria überschriebene Flugschrift, die den deutschen Liedtext Kein Gwalt auf dieser Erd strophenweise abwechselnd mit einer in Distichen abgefassten Übersetzung ins Lateinische wiedergibt. ${ }^{\mathrm{II} 2}$ Auch der lateinische Text bietet ein Akrostichon: CAROLVS QVINTVS COGNOMENTO MAIOR ROMANORVM IMPERATOR CAESAR GERMANICVS AVSTRIACVS SEMPER AVGVSTVS, das wie das deutsche in der Auflösung am äußeren Rand des Drucks noch einmal vermerkt ist. Ein Exemplar dieser Übersetzung muss auch Heinrich Glarean bekannt geworden sein, der nun seinerseits ebenfalls eine lateinische Übersetzung von Kein Gwalt auf dieser Erd anfertigte und drucken ließ. ${ }^{\perp 3}$ Als gründlicher Musiktheoretiker und Schweizer Landsmann ver-

I07 In der Übersetzung Martin Luthers I 545, zitiert nach bibel-online.net.

IO8 Sonja Kerth, „O du armer Judas. Polemik und Parodie in den politischen Ereignisdichtungen des I6. Jahrhunderts", in Glaubensstreit und Gelächter. Reformation und Lachkultur im Mittelalter und in der Frühen Neuzeit, hrsg. von Sonja Kerth und Christoph Auffarth, Berlin 2008 (Religionen in der pluralen Welt. Religionswissenschaftliche Studien 6), S. I35-I 49, hier S. I40.

I09 Etwa verbreitet in der Flugschrift Ein Schön New gemacht Lied/ zu Lob vnd Eer von Gott auffgesetzter Obrigkait, [Augsburg: Heinrich Steiner] I547 [VDi6 ZV I4077], die auch in Würzburg und Leipzig gedruckt wurde [VDI6 ZV I 4078 und S 358I].

I Io Kerth, „O du armer Judas“, S. I 43 und Haug-Moritz, ,ZZu Lob und Ehre““ (wie Anm. IOI).

I I I Vgl. Brednich, Liedpublizistik (wie Anm. I I), Bd. 2 Katalog, Nr. 28I.

I 12 Zunächst erschienen Lied und Übersetzung im Anhang einer von Jacob Kübel dem Bischof von Eichstätt, Moritz von Hutten, gewidmeten Schrift: Iacobi Kvbelii. LL. Doctoris Elegia in fine continens Vaticinivm, [Ingolstadt] I 547 [VDI6 K 2487]. Im Jahr darauf wurde die Cantilena, mit einem Titel versehen, separat von Philipp Ulhardt in Augsburg gedruckt [VDi6 K 45].

I 3 Ain New lied zu eeren Cö. Kayserlich. Mayestat/ Caroli des fünfften, Freiburg im Breisgau: [Stephan Graf?] I 547. [RISM A/I S 2808a; VDi6 N I 3 I 5]; das Exemplar der Bayerischen Staats- 
merkt Glarean auf dem Titelblatt: „Im thon zusingen Mag ich vngluck nit widerstann. Welchen thon etwan Ludwig Senffly vor jaren gemacht." Anders als im Druck der Cantilena imperatoria stehen bei Glarean die deutschsprachige Strophe und lateinische Übersetzung in zwei Spalten nebeneinander. Die Übersetzung weist auch kein Akrostichon auf, dafür liegt ihr ein anderes Konzept zugrunde. Glareans Übersetzung zielt nicht wie diejenige Kübels darauf, die Laudatio auf Karl auch über den deutschen Sprachraum hinaus bekannt zu machen oder ihr eine neue Bedeutungsebene zuzuweisen. ${ }^{14}$ Auf der ersten Rectoseite nach dem Titelblatt ist in zwei Notenzeilen die Melodie Mag ich Unglück, unterlegt mit dem Text der ersten Strophe von Kein Gwalt auf dieser Erd, abgedruckt. Darunter führt Glarean die metrischen Eigenheiten der deutschen Dichtung im Allgemeinen aus und verteidigt ihre Stellung gegenüber der griechischen und lateinischen. Auf der folgenden Seite analysiert er zeilenweise die erste Strophe des Liedes in Anwendung der klassischen lateinischen Begriffe, die am linken Rand angegeben werden. Die Übersetzung orientiert sich nun nicht nur inhaltlich an ihrem Vorbild, sondern richtet sich auch nach dem vom deutschen Text vorgegebenen Metrum. Man könnte also auch den lateinischen Text dem „Lied der Maria von Ungarn“ unterlegen. ${ }^{115}$ Dieser in vielerlei Hinsicht bemerkenswerte Druck im repräsentativen Folioformat wurde von Glarean offensichtlich als Geschenk an Freunde und Kollegen verteilt. Darauf weist ein handschriftlicher Vermerk auf dem Dresdner Exemplar des Drucks hin: „Pro $\mathrm{Su}[\mathrm{m}] \mathrm{mo}$ n[ost]ræ ætatis Theologo D. IOANNE Cochlæo | Glareanus D.M.“. ${ }^{116}$

Im Umkreis der Ereignisse des Schmalkaldischen Krieges entstand eine weitere politisch-historische Kontrafaktur im Ton Mag ich Unglück nit widerstan, die einer Person aus dem kaiserlichen Lager in den Mund gelegt wurde: Mag ich Nachred itzt nicht entgan. ${ }^{117}$ Dieses Lied trägt in Io Strophen das Akrostichon

bibliothek ist online einsehbar unter http://daten.digitale-sammlungen.de/bsbooo3I490/ image_I.

I I $\mathrm{Zu}$ der Verbundenheit Glareans gegenüber Karl V. siehe Franz-Dieter Sauerborn, „,... atque suum familiarem nominarint ‘ Der Humanist Heinrich Glarean (I488-I563) und die Habsburger", in Heinrich Glarean oder: Die Rettung der Musik aus dem Geist der Antike, hrsg. von Nicole Schwindt, Kassel 2006 (TroJa 5), S. 57-75.

I I5 Eine eingehende und aufschlussreiche Betrachtung dieser Publikation, in der Glareans poetische, musiktheoretische und politische Interessen gebündelt aufeinandertreffen, ist Inga Mai Groote, „,Kain Gwalt vff diser Erd“ als hypoaeolische lateinische Ode: Eine unbeachtete Sprachpolemik Heinrich Glareans“, in Bibliothèque d'Humanisme et Renaissance. Travaux et documents 72 (20I0), S. 397-4OI. Ich danke Andrea Horz, dass sie mich auf diesen Aufsatz aufmerksam gemacht hat.

I 6 Das in Details vom Münchner abweichende Exemplar ist online verfügbar unter http://digital.slub-dresden.de/id353989452. Eine Kuriosität stellt der Nachdruck des Glarean'schen Drucks aus dem Jahr I620 in Molßheim dar [VDI7 7:685223Q].

I 7 Liliencron, Die historischen Volkslieder, Bd. 4, Nr. 547. 
MA V R I C I V S Herzog zu Sachsen, die I I. Strophe ist eine Beglaubigung des Inhalts durch eine, sich als der Vortragende des Liedes ausgebende Person. Herzog Moritz von Sachsen unterstützte trotz seiner protestantischen Gesinnung den Kaiser und galt daher dem reformatorischen Lager als Verräter. In Mag ich Nachred itzt nicht entgan sind ihm Klagen über Anfeindungen, denen er sich ausgesetzt fühlt, in den Mund gelegt.

Diese sicherlich noch lückenhafte Darstellung der unterschiedlichen Inkarnationen des Liedes Mag ich Unglück nit widerstan führt vor Augen, welche Faktoren neben der rein musikalischen Qualität über die Karriere und damit die Lebensdauer eines Liedes entscheiden können. Während im I6. Jahrhundert die Person Marias im Vordergrund der Liedgeschichte steht, ist das Weiterleben des Liedes bis ins I9. Jahrhundert vor allem der Aufnahme in die protestantischen Gesangbücher geschuldet. Noch Hans Leo Hassler, Michael Praetorius und Johann Hermann Schein fassten die Melodie in mehrstimmige Sätze. Eine kohärente Darstellung dieser Liedgeschichte erfordert ein angemessenes Maß an Phantasie und ausreichend Mut zu Spekulationen. An ihrem Beginn stehen Melodie und Satz Ludwig Senfls, ${ }^{118}$ der möglicherweise angehalten wurde, einem in Innsbruck ungeduldig der Zukunft harrenden jungen Mädchen eine kleine Freude mit diesem musikalischen Geschenk zu bereiten. Der Liedtext traf jedoch die kommenden Ereignisse in Marias Leben so gut, dass sie das Lied nicht gemeinsam mit der unbelasteten Jugendzeit auf dem ungarischen Thron abstreifen konnte. Die Liebe zu ihrem Gatten und die Katastrophe der Schlacht von Mohács - ein dauerhafter und ein zeitpolitischer Interessensmagnet - machten Maria auch einer breiteren Schicht der deutschsprachigen Bevölkerung bekannt, doch erst das Rätseln um ihre Haltung in der Glaubensfrage - dem zweiten großen zeitpolitischen Thema des Jahrhunderts - verhalf auch ihrem Lied zu neuerlichem Ruhm. Vielleicht über die Vermittlung durch Georg von Brandenburg wird es, losgelöst von Senfls Satz und mit einem neuen Text versehen, in den protestantischen Gebieten verbreitet. Seine Popularität begründet sich nun darin, dass es in den unsicheren Zeiten neben der allgemeinen Hoffnung auf eine bessere Zukunft auch diejenige auf eine mächtige Fürsprecherin für die Sache der Reformation nährt. Mit der Eskalation der Situation im Schmalkaldischen Krieg erlebt Marias Lied einen letzten Karrieresprung. In einem etwas zweideutigen Verhältnis nimmt sich nun das kaiserliche Lager der kirchenpolitisch aufgeladenen Melodie an und nützt sie, um für seine Sache zu werben. Auch die langlebigere

I 8 Auch wenn ich der Angabe Glareans, dass Senfl der Komponist dieser Melodie wäre, nicht blind vertrauen würde (wie es beispielsweise Hans Joachim Moser tat; vgl. Moser, Geschichte, Bd. I [wie Anm. 27], S. 459), gibt es doch keinerlei Hinweise auf ihre Existenz vor I 523. 
Liebe, Tod und Glaubensfragen als Komponenten einer Lied-Karriere im I6. Jahrhundert

Schiene der Liedüberlieferung wurde wohl von Georg von Brandenburg initiiert, indem er das Lied der wittenbergischen „Vermarktungsindustrie“ anvertraute. Ganz im Sinne ihres Großvaters Maximilian war damit, wenn auch auf eher ungewöhnlichen Wegen und von ihr selbst vielleicht sogar skeptisch beäugt, für das „Gedechtnüs“ der Königin Maria von Ungarn gesorgt. 


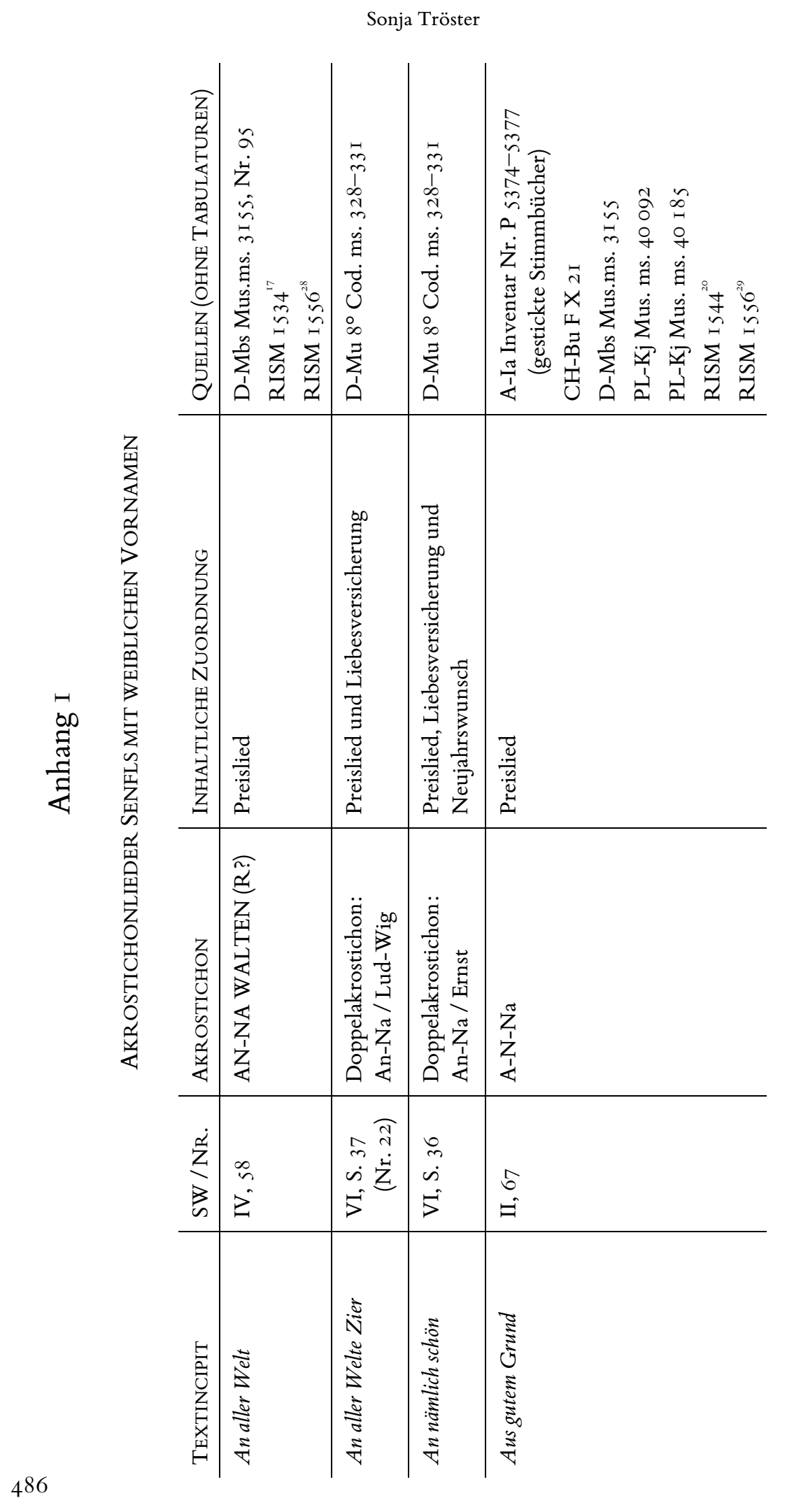


Liebe, Tod und Glaubensfragen als Komponenten einer Lied-Karriere im I6. Jahrhundert

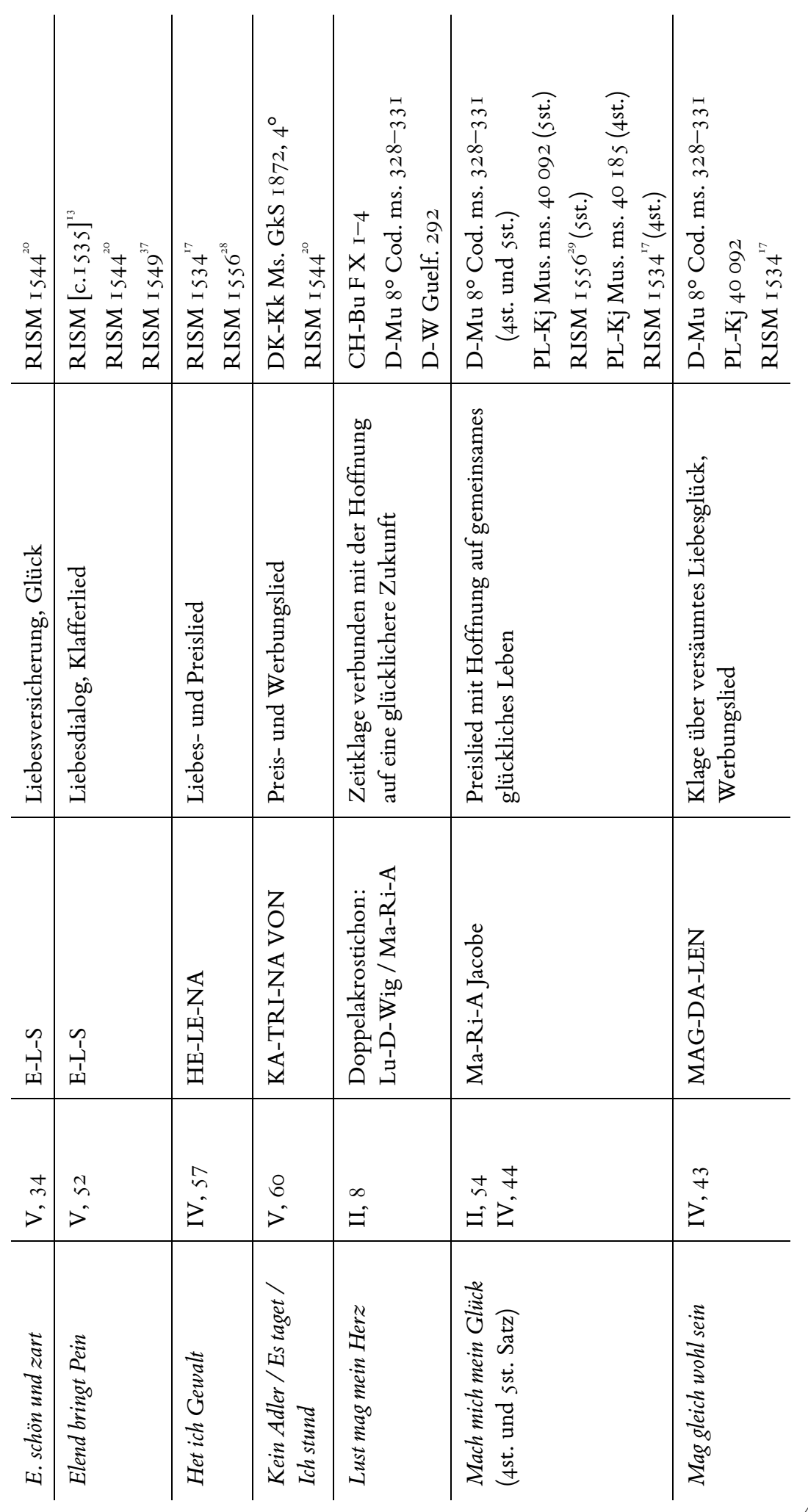


Sonja Tröster

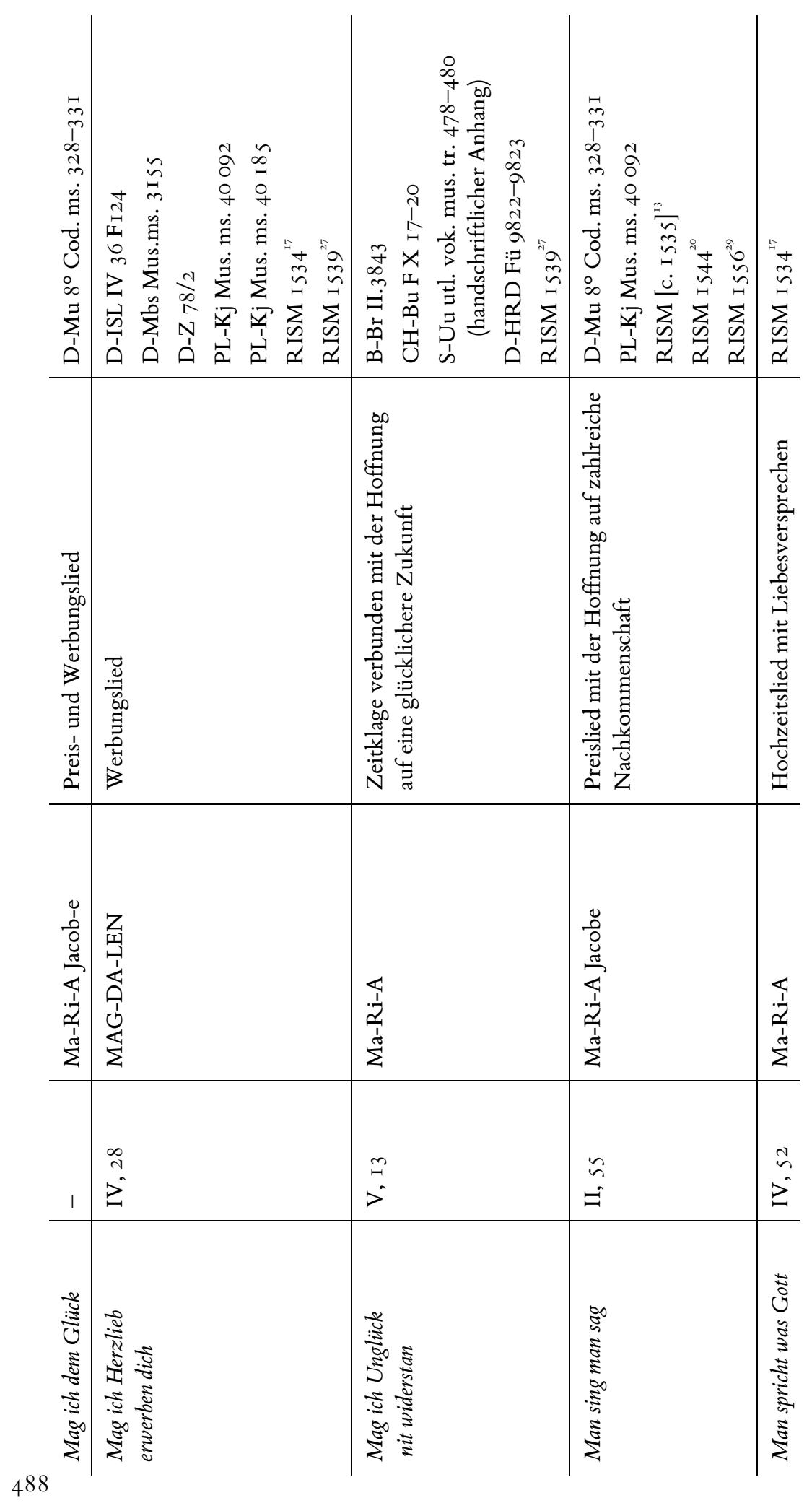


Liebe, Tod und Glaubensfragen als Komponenten einer Lied-Karriere im I6. Jahrhundert

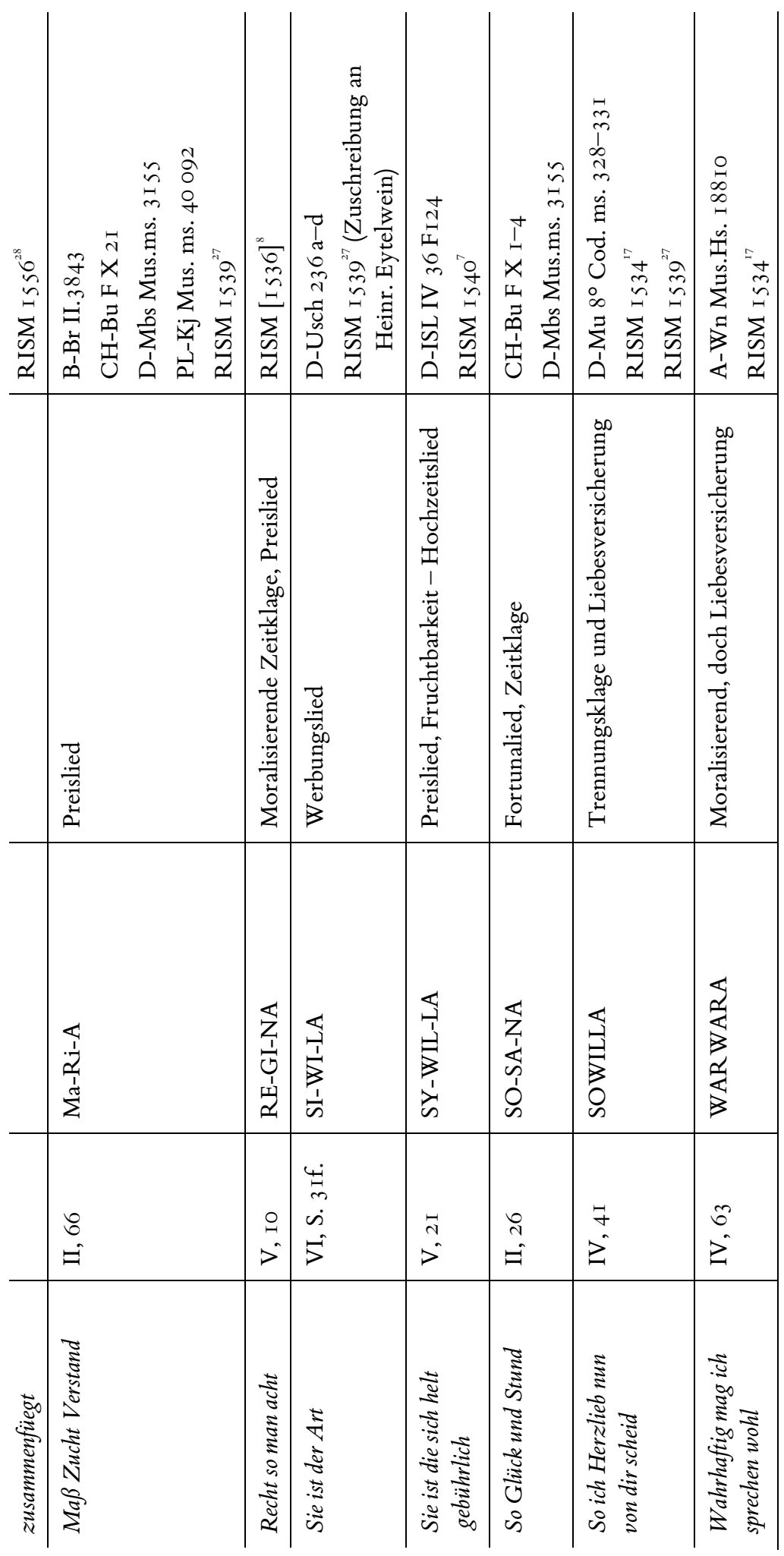




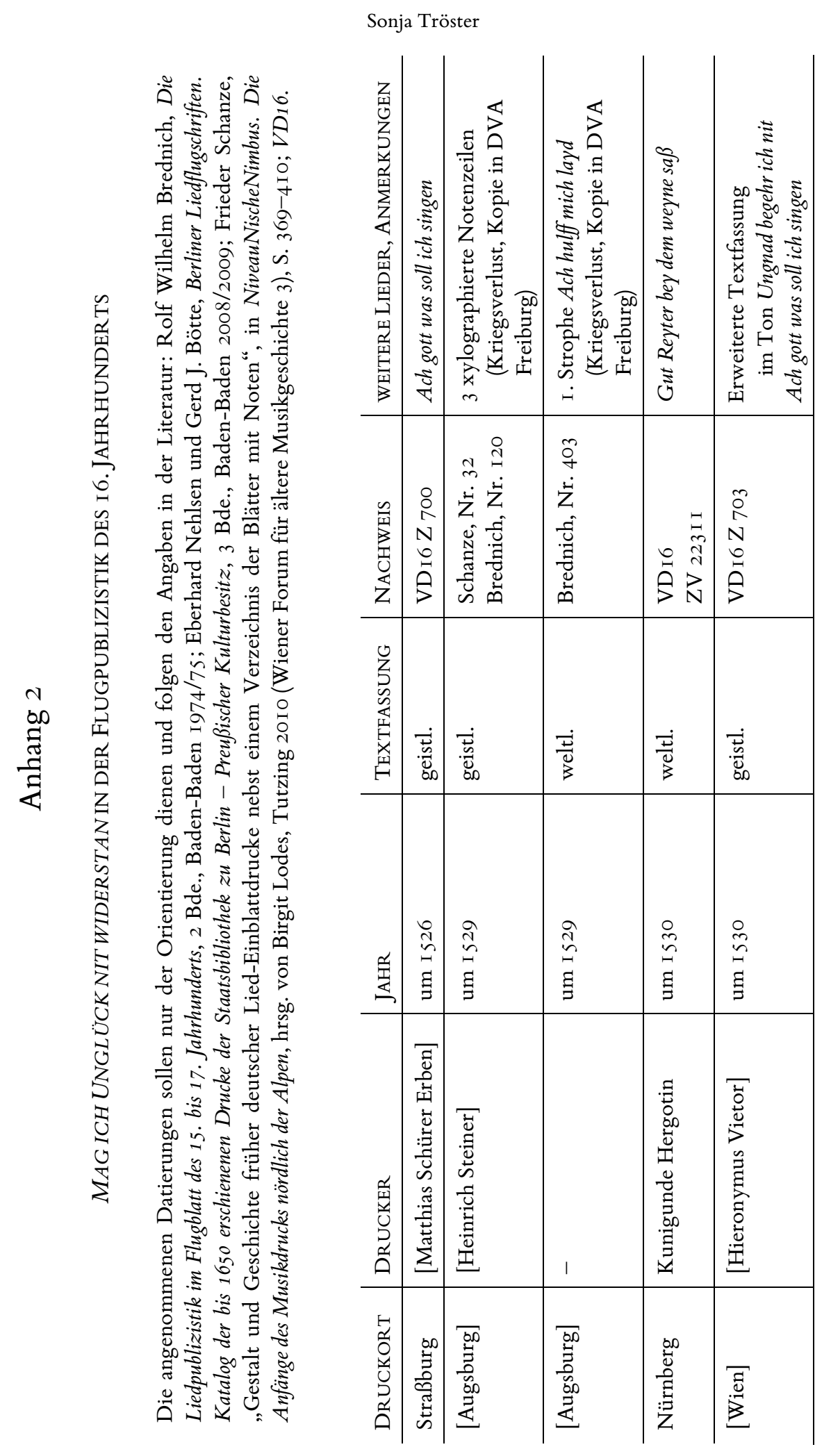


Liebe, Tod und Glaubensfragen als Komponenten einer Lied-Karriere im I6. Jahrhundert

\begin{tabular}{|c|c|c|c|c|}
\hline 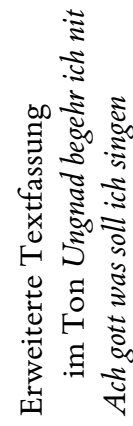 & 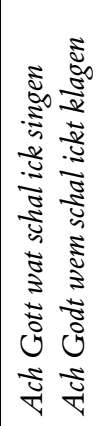 & 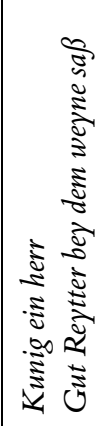 & 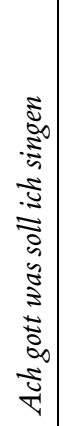 & 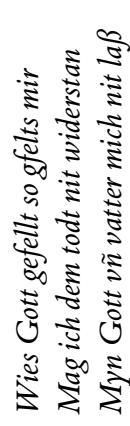 \\
\hline 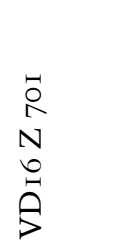 & 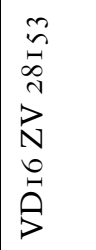 & 1 & 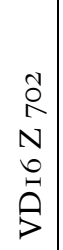 & 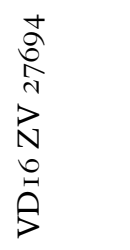 \\
\hline 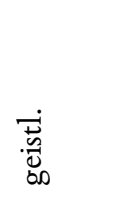 & 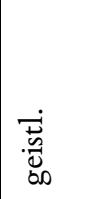 & $\begin{array}{l}\dot{\vec{J}} \\
\dot{0} \\
\dot{3}\end{array}$ & 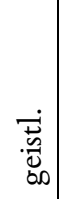 & 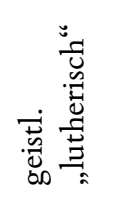 \\
\hline 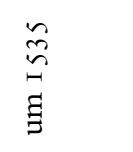 & 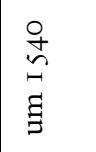 & 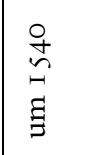 & 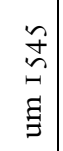 & $\begin{array}{l}\stackrel{0}{a} \\
\stackrel{\Xi}{g}\end{array}$ \\
\hline 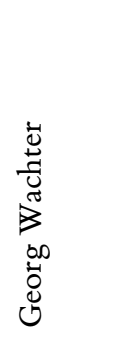 & 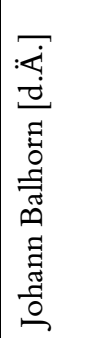 & 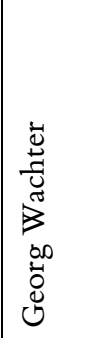 & 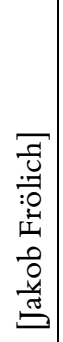 & 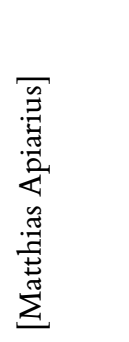 \\
\hline $\begin{array}{l}\text { bo } \\
\dot{\Xi} \\
\vdots \\
\vdots \\
\vdots \\
Z\end{array}$ & 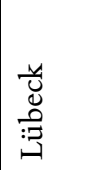 & $\begin{array}{l}\text { bo } \\
\dot{b} \\
\tilde{\Xi} \\
\vdots \\
z\end{array}$ & 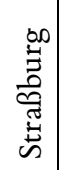 & $\begin{array}{l}\bar{\Xi} \\
\oplus \\
\varrho\end{array}$ \\
\hline
\end{tabular}




\section{Anhang 3}

\section{ÜBERLIEFERUNG DES MEHRSTIMMIGEN SATZES MAG ICH UNGLÜCK NIT WI- DERSTAN VON LUDWIG SENFL}

\begin{tabular}{|c|c|c|}
\hline $\begin{array}{c}\text { QUELLEN IN } \\
\text { MENSURALNOTATION }\end{array}$ & ANMERKUNGEN & DATIERUNG \\
\hline RISM I $539^{27}$, Nr. IO2 & $\begin{array}{l}\text { Zuschreibung: } \text { Lud. Senfl } \\
\text { Nachdrucke: RISM I } 543^{24} \text {, I } 549^{35} \text {, I } 552^{27} \text {, } \\
\text { I } 560^{25}\end{array}$ & I 539 \\
\hline B-Br II. 3843 , Nr. 7 & mit hinzukomponierter 5 . Stimme & I $540-$ I 547 \\
\hline $\begin{array}{l}\text { D-HRD Fü 9822-9823, } \\
\text { Nr. } 30\end{array}$ & nur Diskant und Bass erhalten & Mitte I6. Jh. \\
\hline $\begin{array}{l}\text { S-Uu ms. utl. vok. mus. } \\
\text { tr. } 478-480 \text {, hand- } \\
\text { schriftliche Ergänzung }\end{array}$ & $\begin{array}{l}\text { Diskant fehlt, } \\
\text { kopiert nach RISM I } 543^{24}\end{array}$ & I 545 \\
\hline CH-Bu F X I7-20, Nr. I9 & nur Textincipit & I $545-$ I 560 \\
\hline
\end{tabular}

\begin{tabular}{l|l|l}
\hline Tabulaturen & für Tasteninstrument & \\
\hline $\begin{array}{l}\mathrm{CH}-\mathrm{Zz} \mathrm{Z} \mathrm{XI} \mathrm{30I,} \mathrm{S.} \mathrm{39f.,} \\
\text { fol. } \mathrm{I}^{\mathrm{r}-\mathrm{v}}\end{array}$ & Diskant, Tenor und Bass intavoliert & I 520-I 535 \\
\hline
\end{tabular}

\begin{tabular}{|c|c|c|}
\hline & für Laute & \\
\hline Brown I $523_{2}$, fol. b2 ${ }^{\mathrm{v}}$ & Tenor und Bass intavoliert & I 523 \\
\hline Brown I $523_{2}$, fol. $\mathrm{c}^{\mathrm{v}}-\mathrm{c} 4^{\mathrm{r}}$ & Diskant, Tenor und Bass intavoliert & I 523 \\
\hline Brown I $536_{6}$, fol. e ${ }^{\mathrm{v}}$ & Tenor und Bass intavoliert & I 536 \\
\hline Brown I $54 \mathrm{O}_{\mathrm{I}}$, Nr. 5 & $=$ Brown I $536_{6}($ aber für Laute in $\mathrm{A})$ & I 540 \\
\hline Brown I $544_{2}$, Nr. 6 & $\begin{array}{l}=\text { Brown } \mathrm{I}_{54 \mathrm{O}_{\mathrm{I}}} \text { (mit einigen hinzugefügten } \\
\text { Verzierungen) }\end{array}$ & I 544 \\
\hline $\begin{array}{l}\text { D-Lr Mus. ant. pract. } \\
\text { I I } 96 \text {, fol. } 5\end{array}$ & $\begin{array}{l}\text { Zuschreibung: } L S \\
\text { Die Tabulatur ist derzeit nicht auffindbar. }\end{array}$ & ca. I $540-49$ \\
\hline
\end{tabular}




\begin{abstract}
Mag ich Unglück nit widerstan, which bears the acrostic "Maria" in all its differing text versions, is a Lied that came to be known as the "Song of the Queen of Hungary." Although Mary of Hungary, the sister and confidant of Charles V, never openly confessed to her liking for the Reformation, Mag ich Unglück with a sacred text variant is included in many of the protestant hymnbooks. But the earliest known witness of the Lied is a setting by Ludwig Senfl that for the first time appears in I 523. The popularity of the song itself seems to have been influenced by its connection with major topics of the time which also apply to Mary's life and fate: love, death and questions of faith. The article attempts to gather information for a possible genesis of the text variants of the song, and sets them in relation to other acrostic-songs for members of aristocratic circles. It furthermore pursues the contexts in which the song and various contrafacta were placed in pamphlets throughout the I6th century thus reflecting events in the early years of the Reformation in the German-speaking realm.
\end{abstract}

